\title{
Recent progress regarding kaempferol for the treatment of various diseases (Review)
}

\author{
JIE REN ${ }^{1,2^{*}}$, YIFEI LU ${ }^{1,2^{*}}$, YANHONG QIAN ${ }^{1,2}$, BOZHOU CHEN $^{1,2}$, TAO WU $^{1,2}$ and GUANG JI ${ }^{2}$ \\ ${ }^{1}$ Center of Chinese Medical Therapy and Systems Biology, Institute of Interdisciplinary Integrative Medicine Research, \\ Shanghai University of Traditional Chinese Medicine, Shanghai 201203; ${ }^{2}$ Institute of Digestive Disease, \\ Longhua Hospital, Shanghai University of Traditional Chinese Medicine, Shanghai 200032, P.R. China
}

Received March 3, 2019; Accepted July 16, 2019

DOI: $10.3892 / \mathrm{etm} .2019 .7886$

\begin{abstract}
Kaempferol, also known as kaempferol-3 or kaempferide, is a flavonoid compound that naturally occurs in tea, as well as numerous common vegetables and fruits, including beans, broccoli, cabbage, gooseberries, grapes, kale, strawberries, tomatoes, citrus fruits, brussel sprouts, apples and grapefruit. The present review mainly summarizes the application of kaempferol in treating diseases and the underlying mechanisms that are currently being studied. Due to its anti-inflammatory properties, it may be used to treat numerous acute and chronic inflammation-induced diseases, including intervertebral disc degeneration and colitis, as well as post-menopausal bone loss and acute lung injury. In addition, it has beneficial effects against cancer, liver injury, obesity and diabetes, inhibits vascular endothelial inflammation, protects the cranial nerve and heart function, and may be used for treating fibroproliferative disorders, including hypertrophic scar.
\end{abstract}

\section{Contents}

1. Introduction

2. Anti-inflammatory effects

3. Anti-cancer efficacy

Correspondence to: Dr Guang Ji, Institute of Digestive Disease, Longhua Hospital, Shanghai University of Traditional Chinese Medicine, 725 Wan-Ping Road, Shanghai 200032, P.R. China

E-mail: jiliver@vip.sina.com

Dr Tao Wu, Center of Chinese Medical Therapy and Systems Biology, Institute of Interdisciplinary Integrative Medicine Research, Shanghai University of Traditional Chinese Medicine, 1200 Cai-lun Road, Shanghai 201203, P.R. China

E-mail:wutao001827@163.com

*Contributed equally

Key words: kaempferol, inflammation, cancer, liver injury, obesity, diabetes
4. Application of KP in liver and metabolic diseases

5. KP protects the vascular endothelium

6. KP protects heart function

7. KP protects the cranial nerve

8. KP for fibroproliferative disorders

9. Conclusion

\section{Introduction}

Kaempferol (KP; chemical name, 3,5,7-trihydroxy-2(4-hydroxyphenyl)-4H-1-benzopyran-4-one; also known as kaempferol-3, kaempferide or kaempferol flavonol) is a type of flavonoid. KP has a molecular weight of 286.23 and is a pure yellow crystalline powder with a melting point of $276-278^{\circ} \mathrm{C}$. It is soluble in hot ethanol, ether alkaline, and slightly soluble in water. KP has hydrophobic properties due to its diphenylpropane structure.

The biosynthesis of KP is as follows, under catalysis by chalcone synthase, KP is synthesized by 4-coumaroyl-CoA condensation with tripropionyl-CoA to produce naringenin chalcone (1). Subsequently, naringenin chalcone is transformed into a flavanone called naringenin, which is then hydroxylated by flavanone 3-dioxygenase to produce dihydrokaempferol (2). Finally, by introduction of a double bond at the $\mathrm{C} 2-\mathrm{C} 3$ position in the dihydrokaempferol skeleton, KP is generated.

$\mathrm{KP}$ is a natural flavonol-type flavonoid and can be be isolated from tea as well as numerous common vegetables and fruits, including beans, broccoli, cabbage, gooseberries, grapes, kale, strawberries, tomatoes, citrus fruits, brussel sprouts, apples and grapefruit (3). It has also been identified in different medicinal plants, including Equisetum spp, Sophora japonica, Ginkgo bilobaEuphorbia pekinensis (Rupr.) (3). The most well-known properties of KP are its anti-inflammatory effects. KP has been demonstrated to have beneficial effects on chronic inflammatory diseases, including intervertebral disc (IVD) degeneration, post-menopausal bone loss and colitis, and acute inflammatory diseases, including acute lung injury (ALI). The second most important feature of KP is the prevention of cancer. Its anti-cancer role has been demonstrated in esophageal cancer, breast cancer, cervical cancer, hepatocellular carcinoma (HCC), ovarian cancer, gastric cancer (GC), non-small cell lung cancer (NSCLC), 
leukemia, cholangiocarcinoma (CCA), pancreatic cancer, bladder cancer and osteosarcoma, as well as benign conditions, e.g. uterine fibroids. However, the detailed mechanisms of action of KP against numerous cancer types, as well as its role in improving liver injury, obesity, diabetes and symptoms of metabolic syndrome, have remained elusive. KP may also inhibit vascular endothelial inflammation, preserve the function of the heart, protect the cranial nerve and treat fibroproliferative disorders, including hypertrophic scar (HPS) (Fig. 1).

As a non-toxic, low price dietary ingredient, KP has a very large economic value. As one of flavonoids, it can be extracted from plants. An economic and low cost method for KP preparation is enzymatic hydrolysis, using two KP glycosides in tea seed (4). Additionally, supercritical fluid extraction is also a method for rapidly extracting natural biologically active compounds from plant materials (5). Although poor bioavailability epitomizes a major obstacle, nanotechnology has emerged as a promising means to overcoming this problem (6).

The present review summarizes the role of KP in disease and the current controversy surrounding KP treatment. The aim of this review is to provide evidence for the application of $\mathrm{KP}$ in human diseases in the future.

\section{Anti-inflammatory effects}

In vascular tissues, inflammation is an important biological response, as it reflects tissue damage (7), which is caused by different pathogens, irritants or cell damage (8). KP is a common type of dietary flavonoid with anti-oxidative and anti-inflammatory properties. Studies also indicated that KP decreased lipopolysaccharide (LPS)-induced tumor necrosis factor- $\alpha$ (TNF- $\alpha$ ) and interleukin-1 (IL-1) expression by increasing the number of activated macrophages; suppression of TNF- $\alpha$ mediates the translocation of NF- $\kappa \mathrm{B}$ p65 to the nucleus (9). As inflammation may be classified as acute or chronic, the inflammatory diseases in different categories were discussed separately to understand the role of KP in inflammatory diseases (Fig. 1).

\section{Chronic inflammation}

KP slows IVD degeneration. IVDs are composed of the nucleus pulposus, the annulus fibrosus and cartilage endplates (10), and IVD degeneration has been considered an irreversible process when cell viability decreases, type II collagen is synthesized and the nucleus pulposus is dehydrated (11). Zhu et al (11) demonstrated that KP inhibits LPS-induced apoptosis by inhibiting LPS-induced decreases in the levels of chondrogenic markers which means chondrogenic markers SOX-9, Collagen II and Aggrecan, and reducing the level of matrix-degrading enzymes. In addition, KP also inhibited the expression of lipid anabolism-associated genes. The role of KP in maximally reducing inflammation has also been experimentally validated, as it reduced the levels of pro-inflammatory cytokines and increased anti-inflammatory cytokines, including IL-10, by inhibiting nuclear transcription factors. The above results indicate that KP may be used as a novel treatment for IVD degeneration.

$K P$ may prevent osteoarthritis (OA). OA is the major cause of physical disability with chronic pain (12), which is characterized by the progressive degeneration of articular cartilage along with the depletion of the cartilage matrix (13). It is estimated that 27 million American adults and 8.5 million British adults are diagnosed with $\mathrm{OA}$. The incidence increases with age, with $33.6 \%$ of adults aged 65 being diagnosed with OA $(14,15)$. The progression of OA is closely linked to the overexpression of pro-inflammatory mediators. Numerous studies have suggested that the first-line treatment strategy for $\mathrm{OA}$ is the attenuation of IL-1 $\beta$-stimulated inflammatory mediators (15).

Increased nitric oxide (NO) formation and prostaglandin E2 (PGE2) expression may be major contributors to the development of OA (16) and various studies have documented that stimulation of IL-1 $\beta$ may potentially increase the expression of cyclooxygenase-2 (Cox-2) and inducible NO synthase (iNOS) (17). The NF- $\kappa \mathrm{B}$ signaling pathway is thought to be associated with IL-1 $\beta$-stimulated OA.

In IL-1 $\beta$-stimulated rat chondrocytes as a model of OA, KP caused a reduction in the IL-1 $\beta$-stimulated formation of PGE2 and NO in a KP concentration-dependent manner, and also upregulated the expression of iNOS and Cox-2. The results suggest that $\mathrm{KP}$ has significant anti-inflammatory and anti-arthritis effects by inhibiting the NF- $\kappa \mathrm{B}$ signaling pathway, suggesting that KP may be a novel active therapeutic agent, which may prevent or retard the progression of OA (17).

$K P$ suppresses inflammation in colitis. Ulcerative colitis (UC) is an intractable disease in its chronic persistent form. Park et al (18) have demonstrated that the pathogenesis of UC is associated with an imbalance between pro-inflammatory cytokines and anti-inflammatory cytokines due to activation of the phosphatidylinositol 3-kinase (PI3K)/Akt and NF- $\mathrm{NB}$ signaling pathways that promote pro-inflammatory cytokine expression and secretion.

KP ameliorates mastitis. Mastitis is inflammation of the breast and has the following symptoms: Redness, swelling, pain and warmth, and is classified as non-puerperal mastitis or puerperal mastitis. The incidence rate in lactating women ranges from 10 to $20 \%$ (19). Previous studies have indicated that angiopoietin-like protein 2 (ANGPTL2), which is expressed in adipose tissue, the stomach, skeletal muscle, the heart, the intestines and the uterus, is a decisive factor in mediating acute and chronic inflammation of adipose tissue and in obesity. Therefore, ANGPTL2 may be a beneficial pharmacological target for the treatment of mastitis. Xiao et al (20) reported that treatment with KP may prevent the development of mastitis and decrease myeloperoxidase (MPO), IL-6, TNF- $\alpha$ and ANGPTL2 expression. These results suggest that KP modulates the expression of ANGPTL2 to ameliorate mastitis.

$K P$ inhibits the migration and invasion of fibroblast-like synoviocytes (FLS) in rheumatoid arthritis (RA). $R A$ is a heterogeneous, chronic and systemic autoimmune disease characterized by chronic inflammation (21). Elevated levels of matrix metalloproteinases (MMPs) are important markers in patients with RA, and MMP expression is associated with FLS migration and invasion in RA.

Pan et al (22) demonstrated that KP further inhibited TNF- $\alpha$-induced mitogen-activated protein kinase (MAPK) 


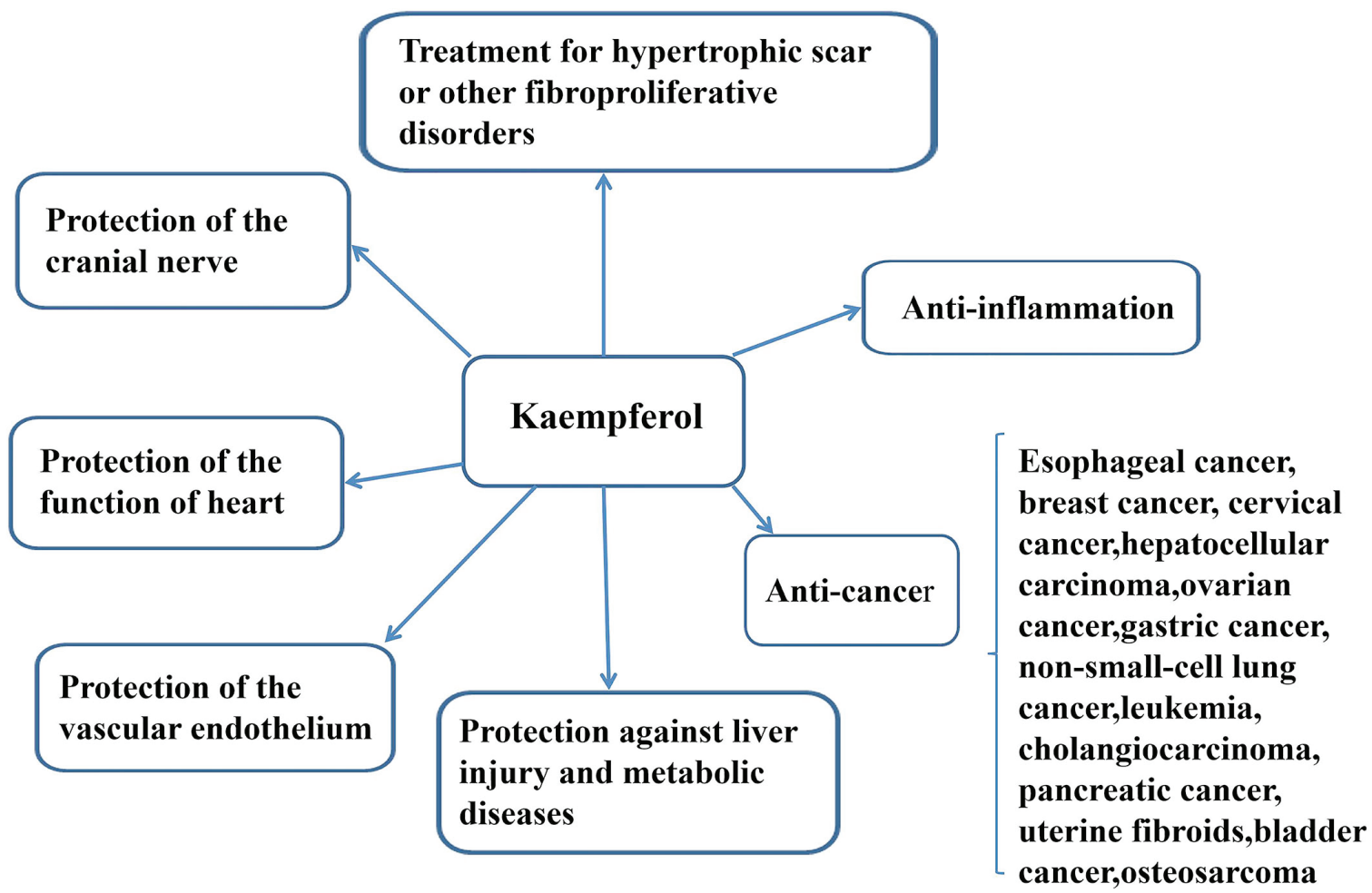

Figure 1. Roles of kaempferol in the treatment of various diseases. Kaempferol has anti-inflammatory and anti-cancer effects, and has been demonstrated to protect the liver and prevent metabolic diseases.

activation without affecting TNF- $\alpha$ receptor expression. They also demonstrated that KP may reduce the severity of arthritis in mice with collagen-induced arthritis. These results indicated that KP inhibits the migration and invasion of FLS in RA by blocking MAPK pathway activation without affecting the expression of TNF- $\alpha$ receptors.

In addition, Lee et al (23) indicated that the basic fibroblast growth factor (bFGF) concentration in the synovial fluid of patients with RA was significantly higher than that in patients with OA. bFGF stimulates the proliferation and migration of human FLS by activating the bFGF-FGF receptor 3 (FGFR3)-ribosomal S6 kinase 2 signaling axis and the molecular docking study indicated that KP inhibits FGFR3 activity by binding to the active pocket of the FGFR3 kinase domain.

\section{Acute inflammation}

$K P$ protects against ALI. Sepsis is a common and serious disease with high morbidity and mortality rates, and is frequently associated with multiple organ dysfunction, particularly acute lung injury (ALI) and acute respiratory distress syndrome (ARDS) (24). In addition, severe hypotension, abnormal blood coagulation and multiple organ dysfunction caused by sepsis may be major risk factors of ALI development (25).

There are various therapeutic strategies for ALI, including NO, surfactant and glucocorticoid administration, but none of them reduce the mortality of patients with sepsis-induced ALI/ARDS (11). The pathophysiological mechanism of ALI/ARDS is thought to be associated with the hyperinduction of cytokines (26), which together promote the migration of polymorphonuclear neutrophils to the pulmonary interstitial and alveolar spaces to cause inflammatory damage by producing reactive oxygen species (ROS) (27). Rabha et al (28) demonstrated that KP reduces the plasma levels of the cytokines IL-6, IL-1 $\beta$ and TNF- $\alpha$, as well as the anti-oxidant enzyme superoxide dismutase (SOD), but did not produce any reduction in the malondialdehyde level and bacterial load.

In addition, the MAPK and NF- $\kappa \mathrm{B}$ signaling pathways have two pivotal roles that contribute to the development of LPS-induced ALI (29). KP may significantly reduce the upregulation of Toll-like receptor 4 (TLR4) and myeloid differentiation factor 88 (MyD88), the phosphorylation level of inhibitor of $N F-\kappa B(I \kappa B \alpha)$ and $N F-\kappa B$ p 65 , the DNA binding activity of $\mathrm{NF}-\kappa \mathrm{B}$ p 65 and the phosphorylation level of MAPKs (27). KP may also suppress airway inflammation, e.g. in asthma, through disturbing $N F-\kappa B$ signaling (30). Airway narrowing is caused by smooth muscle contraction and mucus hypersecretion (31), and the airway epithelium is a target of inflammatory and physical insults, and an effector of ongoing airway inflammation $(32,33)$. The interplay between airway epithelial cells and eosinophils is an essential feature of allergic asthma (30).

Certain studies have indicated that in the development of allergen-induced severe bronchial asthma, endoplasmic-reticulum (ER) stress and the associated signaling networks are important modulators $(34,35)$. KP was proven effective in ameliorating mucus hypersecretion through disturbing the transforming growth factor $\beta$ (TGF- $\beta$ )-triggered ER stress signaling of inositol-requiring enzyme $1 \alpha /$ TNF receptor-associated factor $2 / \mathrm{c}$-Jun N-terminal kinase (JNK) in cellular or animal models of allergic asthma (36).

$K P$ may treat gastric ulcer $(G U)$. One of the most common diseases among average and particularly young individuals is 
GU in Japan, which has been indicated to be as high as 80-82 people per 100,000 inhabitants. However, the incidence rates in Kuwait, Los Angeles, California, the United States and Mexico are very low (37). Acute GU may be caused by alcohol, non-steroidal anti-inflammatory drugs and major stress events, including shock, severe burns, trauma and surgery (38), resulting in severe upper gastrointestinal bleeding (39). It may also develop as a result of the presence of Helicobacter pylori, decreased blood flow, increased acid secretion and pepsin activity, imbalanced bile salt secretion, and reduced mucus and bicarbonate secretion (40). The development of GU arises from an imbalance between aggressive and protective factors present in the gastric mucosa (41).

Several previous studies have demonstrated that pro-inflammatory cytokines, including TNF- $\alpha$, IL- $1 \beta$ and IL-6, have important roles in the regulation of acute GU induced by ethanol (42). In addition, ethanol markedly reduces the level of NO required for physiological functions (43) in the gastric mucosa and decelerates the flow of gastric blood (44). Li et al (45) investigated the protective effects of KP on acute ethanol-induced gastric mucosal injury in mice and the underlying mechanisms. The results indicated that KP may protect the stomach by inhibiting neutrophil accumulation and MPO activity, regulating pro-inflammatory cytokine levels and improving NO production to maintain gastric mucosal glycoprotein levels.

\section{Anti-cancer efficacy}

Cancer is primarily characterized by unrestricted cell proliferation. Surgery, radiation therapy and chemotherapy have been proven to be efficacious in the treatment of certain cancer types, but none of these is a panacea. Since cancer cells tend to have a stubborn inclination to mutate or metastasize, and resistance to treatment is common, it is important to identify safe and effective drugs (5).

KP may exert its anti-cancer effects via several different mechanisms. KP is not only a potent promoter of apoptosis (5), but may also activate the host's immunity, inhibit tumor blood vessel growth and increase the sensitivity of other anti-cancer drugs.

Arif et al (46) explained that another anti-cancer mechanism of flavonoids is the increase in cellular DNA breakage; furthermore, flavonoids act as pro-oxidants in the presence of transition metal ions, including copper. Flavonoid treatment may make cancer cells more susceptible to copper-induced oxidative DNA breakage. This copper-dependent oxidative cytotoxic mechanism may be a better explanation of the anti-cancer activity and preferential cytotoxicity of dietary phytochemicals, which may be beneficial in the treatment of cancer.

Esophageal cancer. Esophageal cancer is the eighth most common cancer type in the world and the sixth leading cause of cancer-associated death. From a histological perspective, it includes esophageal squamous cell carcinoma and adenocarcinoma (47). However, difference are observed between the two tumors. Esophageal cancer risk factors include smoking and alcohol abuse, while adenocarcinoma is associated with obesity and gastroesophageal reflux disease (48). It has been indicated that KP is able to inhibit tumor cell proliferation and in vitro clonal formation, and induces $\mathrm{G} 0 / \mathrm{G} 1$ phase arrest of tumor cells (49). Furthermore, KP has a substantial inhibitory effect against tumor glycolysis (49), and it may upregulate the expression of B-cell lymphoma-2 (Bcl-2) associated X protein (Bax) and other pro-apoptotic genes through the mitochondrial signaling pathway, downregulate Bcl-2 and inhibit the expression of caspase-9. Inhibition of caspase- 9 expression further activates caspase-3, triggering a cascade of caspases, which triggers apoptosis (49). KP can also be applied to the human oesophageal adenocarcinoma cell line. A previous study demonstrated that with flavones treatment, G2/M arrest can be caused through the upregulation of GADD $45 \beta$ and $14-3-3 \mathrm{~s} Q$ and the downregulation of cyclin B1 at the mRNA and protein levels, and can induce p53-independent mitochondrial-mediated apoptosis through the upregulation of PIG3 and the cleavage of caspase-9 and caspase-3 (50). These results indicate that KP can be used for the treatment of esophageal cancer.

Breast cancer. Cancer is becoming one of the most malignant diseases in the world, with $>12.5$ million new cases and 7.5 million deaths per year (51). Breast cancer is an estrogen-associated cancer type, and its development and progression are mainly linked to the multiple effects of estrogen through the estrogen receptor (52). Previous studies have indicated that flavonoids may inhibit the growth of breast cancer cells in vitro and in vivo by competing for the estrogen binding site of $17 \beta$-estradiol (E2) and the estrogen receptor (53).

Kim et al (52) reported that KP inhibits breast cancer by suppressing cancer progression induced by triclosan (TCS) and E2 through acting as an antagonist for estrogen receptor and insulin-like growth factor (IGF) 1 receptor signaling. It has been suggested that KP-3-O-rhamnoside triggers cell death intrinsically in MCF-7 cells via the mitochondrial caspase-9 signaling pathway and activation of poly ADP-ribose polymerase (PARP) (54). These results demonstrate that KP has an anti-cancer effect to antagonize the pro-cancer activity of E2 or TCS (52).

Li et al (55) reported that KP inhibited the invasion of breast cancer cells by blocking the protein kinase $\mathrm{C}$ (PKC)/MAPK/activator protein-1AP-1 cascade, and the subsequent expression and activity of MMPs; it also inhibited TCS-induced MCF-7 breast cancer cells. Yi et al (56) obtained similar results, as incubation of MCF-7 cells with 40 and $80 \mu \mathrm{M}$ $\mathrm{KP}$ for $24 \mathrm{~h}$ resulted in numerous cells that possessed smaller nuclei with chromatin condensation and perinuclear apoptotic bodies. It was indicated that 40 and $80 \mu \mathrm{M}$ KP may induce PARP cleavage in a dose-dependent manner.

By analyzing the effects of KP on apoptosis and DNA damage, Zhu et al (57) revealed that it effectively inhibited the proliferation of the triple-negative breast cancer cell line malondialdehyde (MDA)-MB-231; this effect was stronger in MDA-MB-231 cells than in the estrogen receptor-positive BT474 cell line. These results indicated that KP may be a potential drug for the effective treatment of breast cancer.

Cervical cancer. Cervical cancer ranks as the fourth most frequently diagnosed cancer and the fourth leading cause of 
cancer death in women, with an estimated 570,000 cases and 311,000 deaths in 2018, worldwide. Cases are concentrated in Sub-Saharan Africa and South-Eastern Asia (58).

Kashafi et al (59) indicated that KP decreased cell viability in a concentration-and time-dependent manner. They demonstrated that after incubation with $\mathrm{KP}$, telomerase and the PI3K/AKT signaling pathway were inhibited, and apoptosis was induced via p53 and Bax/Bcl-2 in HeLa cervical cancer cells in a time- and concentration-dependent manner, whereas this was not observed in normal cells. There was no significant toxic effect, which is a key advantage in the treatment of cervical cancer.

HCC. HCC is the most common type of primary liver cancer (60). Early treatment for HCC is transplantation, surgical resection or local ablation (61). An important cause of HCC development is angiogenesis and the RAF kinase/MAPK kinase (MEK)/MAPK signaling pathway that regulates cell proliferation (62). Other developmental factors in HCC are increased cell proliferation and limited blood supply. Hypoxia-inducible factor-1 is a key component of adaptation to oxygen deprivation (63). At present, due to its anti-tumor properties, KP has been proposed as a potential agent for HCC treatment and activation of the ER stress-CCAAT/enhancer-binding protein homologous protein (CHOP) signaling pathway may be one of the molecular mechanisms of KP-induced hepatocellular apoptosis (60). Mylonis et al (64) demonstrated that KP reduces the survival of liver cancer cells more effectively under hypoxic conditions. Seydi et al (65) reported that KP induces selective cytotoxicity on hepatocytes in HCC in a dose- and time-dependent manner, and also increases the activation of caspase-3. Of note, KP is not toxic to healthy liver cells and mitochondria. Therefore, KP is a good candidate for supplemental anti-HCC treatment.

Ovarian cancer. It was estimated that in 2010, almost 850 females in the US died from ovarian cancer, accounting for $5 \%$ of total cancer-associated mortalities in females (66). The key approach to the prevention of ovarian cancer is based on environmental factors rather than genetic backgrounds (66).

Numerous studies have demonstrated that several types of cancer cell, including ovarian cancer, pancreatic cancer, gliomas, malignant melanoma and neuroblastoma, are TNF-related apoptosis-inducing ligand (TRAIL) resistant (67). Increased expression of anti-apoptotic proteins, including X-linked inhibitor of apoptosis protein, Bcl-2 and decoy receptors, have been associated with TRAIL resistance (68). Furthermore, identifying TRAIL sensitizers is crucial in cancer therapy, as the NF- $\mathrm{B}, \mathrm{PI} 3 \mathrm{~K} / \mathrm{Akt}$ and MAPK signaling pathways have all been implicated in the resistance to TRAIL-induced apoptosis (67).

It was demonstrated that KP is able to regulate pro-apoptotic and anti-apoptotic protein expression by inducing apoptosis in A2780/CP70, A2780/WT and OVCAR-3 ovarian cancer cell lines (66). This result was in line with a study by Zhao et al (69), which indicated that KP was able to enhance apoptosis and upregulate drought-repressed (DR)4, DR5, CHOP, JNK, ERK1/2, p38 and apoptotic protein expression. RNA silencing experiments indicated the involvement of
CHOP in DR5 upregulation and also the contribution of DR5 in KP-enhanced TRAIL-induced apoptosis.

In the cell cycle, checkpoint kinase 2 (Chk2) is a stably expressed serine/threonine kinase and also a tumor suppressor that regulates a variety of essential cellular functions (70). Mutations and/or deletions in Chk 2 are associated with multiple cancer types (70). Gao et al (71) demonstrated that $\mathrm{KP}$ induces cell cycle arrest in G2/M phase via the Chk2/cell division cycle (CDC)25C/cell division control 2 signaling pathway. These results reflect the anti-ovarian cancer properties of KP, which will be a potential option for the treatment of ovarian cancer.

$G C$. GC is the fourth most common type of malignancy worldwide and ranks second in terms of cancer-associated mortality (72). Surgery is currently the major treatment. Cytotoxic chemotherapy has proven to be an effective treatment for advanced stages when surgery is not feasible (73). However, long-term chemotherapy leads to drug resistance and treatment-associated side effects (74). Therefore, there is a requirement for more effective anti-tumor drugs with fewer side effects.

A previous study indicated that $\mathrm{KP}$ effectively inhibits the proliferation of GC cells. They observed that GC cells were arrested in $\mathrm{G} 2 / \mathrm{M}$ phase, and the expression levels of cyclin-dependent kinase 1 and CDC25C were decreased after KP treatment. In addition, KP inhibited the ERK1/2 and PI3K/AKT signaling pathways. Therefore, KP may be considered to have potential therapeutic effects in GC.

NSCLC. NSCLC is the leading cause of cancer-associated death worldwide each year and its prognosis is poor (75). In addition, the major cause of death in patients with lung cancer is the metastasis of lung cancer cells. TGF- $\beta 1$ is a typical member of the TGF- $\beta$ superfamily, the function of which is regulated cell proliferation, differentiation, apoptosis and migration (76). TGF- $\beta 1$ has been proved to inhibit tumor function, act as a metastasis-inducing agent by inhibiting cell proliferation and promoting apoptosis, and also promote endothelial-to-mesenchymal transition (EMT) in advanced cancers (76). Jo et al (77) suggested that KP inhibits TGF- $\beta 1$-induced EMT and cell migration in human lung cancer cells by targeting the phosphorylation of the 3 linker region of SMAD family members, and this pharmacological inhibition may provide an effective barrier to lung cancer progression.

Leukemia. Leukemia occurs in the blood and bone marrow. It develops if blood-forming cells lack the ability to control their growth (75). Leukemia has various subtypes, including acute lymphocytic leukemia, acute myeloid leukemia, acute promyelocytic leukemia (APL), chronic lymphocytic leukemia and chronic myeloid leukemia (78). It has been indicated that KP inhibits the growth of human leukemia mast cells by inhibiting DNA repair protein expression in HL-60 human leukemic cells, including p-ataxia telangiectasia mutated, p-ataxia telangiectasia Rad3, BRCA-1, 14-3-3-like protein B, DNA-dependent protein kinase and O-6-methylguanine-DNA methyltransferase (79).

In APL, fusion between retinoic acid receptor- $\alpha$ and promyelocytic leukemia genes is common (80). Previous 
studies indicated that KP increased apoptosis and inhibited telomerase expression (59). Another study suggested that KP induced apoptosis by inhibiting multidrug resistance protein and increasing the $\mathrm{Bax} / \mathrm{Bcl}-2$ ratio; the cytotoxic effect of KP was more pronounced in leukemia cells than in normal human polymorphonuclear leukocytes (81).

$C C A$. CCA is the most common biliary malignancy in the world. It has been reported that KP induces apoptosis through regulating Bcl-2 and caspase family proteins (82). Qin et al (83) confirmed that KP markedly reduced the expression of Bcl-2, while it increased the expression of Bax, cell surface death receptor, cleaved-caspase-3, cleaved-caspase-8, cleaved-caspase- 9 and cleaved-PARP. In addition, KP was indicated to induce apoptosis via the fas cell surface death receptor death receptor/caspase signaling pathway, and the pan-caspase inhibitor Q-VD-OPH inhibited KP-mediated caspase-3 and PARP activation, as well as KP-induced apoptosis.

Upregulation of MMP2 and MMP9 is also key to the invasion of CCA cells into surrounding tissues. The study by Qin et al (83) indicated that the KP-treated groups had decreased MMP2 expression and increased expression of tissue inhibitor of metalloproteinase 2 (TIMP2), whereas there was no significant change in the expression of MMP9 and TIMP1.

In summary, $\mathrm{KP}$ is effective against CCA in vitro and in vivo. Inactivation of the PI3K/AKT signaling pathway and downstream proteins may be the mechanism by which KP exerts its effects against CCA and prevents its progression.

The 5-year survival rate of patients with pancreatic cancer is $<1 \%$ (84). Early local tumor spread and progression are the major features of pancreatic cancer (76).

Key factors in aggressive pancreatic cancer are epidermal growth factor receptor (EGFR) and hepatocyte growth factor receptor $(85,86)$. It has been demonstrated that KP is able to reduce EGFR and SRC proto-oncogene expression, as well as the activation of the AKT and ERK1/2 signaling pathways to inhibit the growth and migration of pancreatic cancer cells by blocking EGFR-associated pathways in vitro (87).

Uterine fibroids. Uterine fibroids are most common in females between 30 and 50 years of age. Uterine fibroids are benign tumors and are considered a hormone-dependent disease, but the exact cause remains elusive (88). The most common treatment of uterine fibroids is surgical resection, but this affects the health of the patients. Flavonoids have been indicated to have anti-inflammatory and anti-tumor effects, and may be used in the treatment of uterine fibroids (89).

Li et al (89) indicated that treatment with KP reduces the expression of the estrogen receptor, IGF-1 and vascular endothelial growth factor precursor (VEGF) at the mRNA and protein level by inhibiting the proliferation of human uterine fibroid cells in vitro. However, the effect of KP on the apoptosis of human uterine fibroid cells remains elusive. In the above study, KP effectively reduced the levels of myocardin in uterine fibroids compared to normal uterine smooth muscle. Myocardin expression is the major auxiliary factor of the transcription factor serum response factor, which acts on the differentiation of smooth muscle cells (88).
Bladder cancer. Bladder cancer is a common type of malignant tumor of the urinary system. Previous evidence has suggested that the methylation of genomic DNA is closely linked to bladder cancer (90). Therefore, modulating DNA methylation with potent and low toxicity agents is a key strategy to prevent and treat cancer $(91,92)$.

DNA methyltransferases (DNMTs) are key enzymes in the regulation of DNA methylation, which mostly relies on the expression of DNMTs. Lee et al (93) indicated that KP promotes the degradation of DNMT3B, which is closely linked to the Ub-proteasome pathway in bladder cancer. A previous study suggested that KP inhibits the activation of the PI3K/Akt signaling pathway through increasing the tumor suppressor phosphatase and tensin homolog in bladder cancer (88). These results indicate that the downregulation of DNMT3B may be linked to the PI3K/Akt-associated Ub-proteasome signaling pathway. Therefore, a novel DNMT3B inhibitor, including KP, may be considered for bladder cancer, which promotes DNA methylation and downregulates DNMT3B levels by promoting the degradation of its Ub proteasome (90).

$O S$. OS is a malignant type of bone tumor and mainly arises from the malignant transformation of mesenchymal cells (94); it mostly affects children and young adults (95). Huang et al (96) demonstrated that KP significantly reduced the viability of U-2 OS cells, human osteoblasts and 143B cells, but exerted low cytotoxicity on human fetal osteoblast progenitor and human fetal osteoblastic cells. KP induced tumor cell apoptosis and inhibited tumor cell proliferation through mitochondria-dependent and ER stress signaling pathways. Chen et al (97) indicated that KP decreased the expression of MMP-2, MMP-9 and urokinase plasminogen activator at the protein levels, inhibited the invasion and adhesion of OS cells and the migration of U-2 OS cells in a concentration-dependent manner. These results demonstrated that following KP treatment with $100 \mu \mathrm{M}$, the inhibition rate reached $>60 \%$.

\section{Application of KP in liver and metabolic diseases}

KP protects against hepatotoxicity. As the first organ that metabolizes foreign compounds, the liver is vulnerable to various diseases, including hepatitis, cirrhosis or HCC (98). One of the most common liver diseases caused by drugs is hepatitis induced by anti-tuberculosis (TB) drugs (99). Drug-induced hepatotoxicity may be due to oxidative stress caused by the production of toxic metabolites or free radicals (100). The primary pathway of inhibitor of isoniazid (INH) metabolism by $\mathrm{N}$-acetyltransferase 2 generates acetyl-INH. Acetyl-INH undergoes hydrolysis to form acetyl-hydrazine and the nontoxic substance isonicotinic acid, which is oxidized by cytochrome P450 family 2 subfamily E member 1 (CYP2E1) to form reactive acylating hepatotoxins or its breakdown products (99).

Shih et al (101) demonstrated that KP significantly reduced liver glutathione consumption and prevented an increase of malondialdehyde formation in mice. In addition, KP did not affect the anti-TB effect of INH/rifampicin.

Carbon tetrachloride $\left(\mathrm{CCl}_{4}\right)$ is a xenobiotic, which produces hepatotoxicity in humans and various experimental 
animals (102). $\mathrm{CCI}_{4}$ can be activated by cytochrome P450-dependent monooxygenases to form highly reactive radicals and exhibit DNA damage and lipid peroxidation (103). In a previous study, a hepatic toxicity model was induced by carbon $\mathrm{CCl}_{4}$ in mice. $\mathrm{CCl}_{4}$ induces lipid peroxidation, which causes membrane breakdown of hepatocytes to subsequently release marker enzymes of hepatotoxicity (104). It has indicated that after KP 3-O-rutinoside and KP 3-O-glucoside treatment, serum total protein levels were increased, induction of serum aspartate aminotransferase serum alkaline phosphatase and liver malondialdehyde levels by $\mathrm{CCl}_{4}$ was prevented (105). In addition, glutathione levels were significantly restored, and normal catalase and SOD activities were observed. KP 3-O-rutinoside and KP 3-O-glucoside have protective effects against acute $\mathrm{CCl} 4$-induced oxidative liver damage.

$K P$ protects against alcoholic liver injury. Alcoholic liver injury is one of the major health problems in the world, accounting for $\sim 4 \%$ of the total global death toll (106). High alcohol consumption leads to hepatotoxicity associated with oxidative stress due to the promotion of ROS production and reduction of anti-oxidant effects (107). Studies have indicated that CYP2E1 is an important factor in alcohol-induced liver injury, as it is highly inducible and has a high catalytic activity for alcohol (108).

Wang et al (107) indicated that KP attenuates the activity and expression of CYP2E1, enhances the protective effect of the anti-oxidant defense system and may thus protect the liver from alcoholic liver injury. KP increased anti-oxidant effects and also reduced ROS production through inhibiting CYP2E1. Although KP was demonstrated to reduce lipid accumulation in non-alcoholic fatty liver disease, its application in clinical treatment of alcoholic liver disease remains to be evaluated (107). Zhou et al (109) indicated that the protein levels of CYP2E1 in microsomes and mitochondria, heat shock protein 70 (Hsp70) in the cytosol and specificity protein 1 (SP1) in the nucleus and cytosol were reduced in the KP-treated group, and KP also increased the cell viability compared with that in the ethanol-treated group. The study also suggested that the mechanism of the protective effect of KP against ethanol-induced primary hepatocyte injury involved mitochondrial and microsomal CYP2E1, cytosolic Hsp70, and nuclear and cytosolic SP1 (109).

$K P$ suppresses obesity. Obesity is a common chronic disease characterized by excessive fat deposits in adipose tissue or other internal organs, including the liver, heart, skeletal muscle and islets (110). Simple obesity may induce all symptoms of metabolic syndrome, including insulin resistance, nonalcoholic fatty liver, atherosclerosis and degenerative diseases, e.g. dementia (111).

Experiments have suggested that KP inhibits lipid accumulation and increases fatty acid oxidation signaling in adipocytes. KP reduced cytoplasmic triglyceride accumulation during adipocyte differentiation in a time- and dose-dependent manner. KP broadly reduced the mRNA or protein levels of adipogenic transcription factors and their lipid accumulation-associated target genes, thereby inhibiting glucose uptake and the expression of glucose transporter solute carrier family 4 mRNA in adipocytes (112).
KP also reduces the accumulation of visceral fat by increasing lipid metabolism through downregulation of sterol regulatory element-binding proteins, and promoting the hepatic expression of acyl-CoA oxidase and CYP450, family 4, subfamily a, polypeptide 1 (113).

$K P$ improves diabetes. Luo et al (114) reported that KP-mediated downregulation of $\mathrm{I} \kappa \mathrm{B} \alpha$ and inhibition of NF- $\kappa \mathrm{B}$ pathway activation may lead to a reduction in hepatic inflammatory lesions, which may help to improve insulin signaling deficits in patients with diabetes. Chen et al (115) indicated that KP significantly inhibited inflammatory cytokine expression and high glucose-induced ROS production. KP exerted protective effects in diabetic cardiomyopathy by suppressing nuclear translocation of NF- $\kappa \mathrm{B}$ and activating NF-erythroid 2 p45-related factor-2.

In addition, KP may protect $\beta$-cells from glucose toxicity and mediate anti-apoptotic effects by improving cyclic adenosine monophosphate (cAMP)/protein kinase A and PI3K/Akt signaling pathways. Zhang and Liu (116) indicated that KP treatment promoted cell viability, inhibited apoptosis and reduced caspase- 3 activity in $\beta$-cells and human islets chronically exposed to hyperglycemic conditions.

Furthermore, diabetes mellitus has been indicated to increase the susceptibility of the myocardium to ischemia-reperfusion (I/R) injury. It has been demonstrated that advanced glycation end products (AGE) take part in the pathogenesis of diabetic complications in various organs, including the heart (117). Suchal et al (118) indicated that KP is involved in maintaining hemodynamic function, inhibiting AGE-receptor axis activation, normalizing oxidative stress and maintaining morphological changes. Their results suggested that diabetic I/R group significantly reduced arterial pressure and heart rate. Additionally, ventricular dysfunction was exhibited through decreasing ventricular and relaxation and increasing preload. The levels of inflammatory markers, including TNF- $\alpha$, IL-6 and $\mathrm{NF}-\kappa \mathrm{B}$, were decreased, and that the activity of JNK, p38 and ERK1/2 was inhibited. For a period of 28 days, KP significantly suppressed the activation of AGEs-RAGE, which is the receptor of AGE. Furthermore, KP inhibited apoptosis by reducing the expression of pro-apoptotic proteins, including Bax and caspase-3, decreasing the expression of pro-apoptotic protein and terminal deoxynucleotidyl transferase dUTP nick end labeling positive cells and increasing the expression of Bcl-2. In conclusion, KP significantly ameliorated IR-induced myocardial injury via the normalization of hemodynamic parameters, maintaining oxidant antioxidant status, reducing inflammation and apoptosis and by inhibiting the MAPK/AGE-RAGE pathways.

Alkhalidy et al (119) reported that KP treatment increased Akt and hexokinase activity, while decreasing pyruvate carboxylase (PC) and glucose- 6 phosphatase activity in the liver without altering the protein expression. At the same time, $\mathrm{KP}$ reduced $\mathrm{PC}$ activity and inhibited gluconeogenesis of HepG2 hepatoblastoma cells and primary hepatocytes isolated from the liver of obese mice.

Another noteworthy point is that KP is able to alleviate diabetic neuropathic pain. Kishore et al (120) indicated that $\mathrm{KP}$ corrected hyperglycemia in diabetic rats and partially reversed pain responses by regulating oxidative and nitrosative 
stress, and reducing AGE formation in diabetic rats. These results indicate that KP may be a naturally occurring anti-diabetic compound and may be applied to help treat diabetic neuropathic pain.

KP ameliorates symptoms of metabolic syndrome. Metabolic syndrome is a complex disease, and the risk of cardiovascular disease and type 2 diabetes is significantly increased in patients with metabolic syndrome (99). It has been suggested that one possible way to prevent and ameliorate these complex symptoms is to activate the liver $\mathrm{X}$ receptor (LXR), which was identified as a transcription factor that regulates hepatic gluconeogenesis (121).

Chang et al (113) demonstrated that KP directly interacts with LXR- $\alpha$ and LXR- $\beta$ proteins. In obese apolipoprotein $\mathrm{E}$ (ApoE)-deficient mice fed a high-fat diet, administration of KP significantly reduced plasma glucose and triglyceride levels, increased high-density lipoprotein cholesterol levels, and improved insulin sensitivity and glucose tolerance. Furthermore, KP did not induce hepatic steatosis, as it inhibited post-translational activation of the precursor forms of sterol regulatory element-binding protein-1 (pSREBP-1) to form the nuclear isoform of SREBP-1. Selective activation of LXR- $\beta$, whose expression level is low in the liver, may contribute to the avoidance of hepatic lipogenesis.

In conclusion, KP independently regulates LXR- $\beta$ and peroxisome proliferator-activated receptor $\alpha$, and improves the overall metabolic status. These results may contribute to the treatment of metabolic syndrome (122).

\section{KP protects the vascular endothelium}

$K P$ inhibits vascular endothelial inflammation. The vascular endothelium may be considered a dynamic barrier that selectively inhibits the movement of plasma and cells from the blood into adjacent tissues (123). Inhibition of vascular endothelial inflammation is considered a key point in the treatment of numerous vascular diseases, as excessively produced inflammatory mediators may cause irreversible vascular damage and lead to excessive loss of fluid from the circulation, resulting in insufficient tissue perfusion, organ dysfunction and death (123).

Kim et al (124) reported that KP inhibited the pro-inflammatory response, which was mediated by LPS or high mobility group box 1 (HMGB1) by increasing barrier integrity and inhibiting the expression of cell adhesion molecules. Therefore, the anti-inflammatory properties of KP are considered to be based on downregulation of the HMGB1 receptors TLR2 and TLR4, and this may have a beneficial effect in the treatment of vascular diseases.

KP inhibits vascular smooth muscle cell (VSMC) migration. VSMCs retain the ability to switch between differentiated and dedifferentiated phenotypes, in response to environmental conditions including growth factor stimulation or vascular injury (123). TGF- $\beta$ and bone morphogenetic protein (BMP)4 are important factors that inhibit VSMC proliferation and migration, increase the expression of contractile VSMC gene and promote the contractile phenotype (125). This phenotype may be switched to another phenotype via the platelet-derived growth factor (PDGF) signaling pathway (126). PDGF may lead to resistance to TGF- $\beta$ and BMP signaling and promote the synthetic phenotype.

Kim et al (127) indicated that KP may activate the BMP signaling pathway, induce microRNA (miR)-21 expression and downregulate dedicator of cytokinesis 4 (DOCK4), DOCK5 and DOCK7, thereby inhibiting cell migration and antagonizing PDGF-mediated migration. KP may be considered a potential therapeutic for cardiovascular diseases, as it inhibits VSMC migration by modulating BMP-mediated miR-21 expression and $\mathrm{miR}$ regulation.

$K P$ prevents atherosclerosis. Atherosclerotic cardiovascular disease is one of the leading causes of mortality worldwide (128). Endothelial cells, macrophages and smooth muscle cells are the major cell types involved in atherosclerosis (129).

Osteopontin (OPN) together with its CD44 is generally considered to be a key molecule in atherosclerosis (130). Xiao et al (131) performed analysis of the aorta and plasma from C57BL/6J control and ApoE-deficient mice treated with or without KP. This aforementioned study reported that, prior to the experiment, the expression of OPN and CD44, the production of aortic ROS and the area of atherosclerotic lesions were higher compared with the control group in the ApoE-deficient mice with KP. For 4 weeks, KP significantly reduced atherosclerotic lesion formation compared with mice treated with vehicle, restored vasodilatation in response to acetylcholine, enhanced the Emax value and reduced the EC50 value. The plasma level of OPN and the expression of aortic OPN and CD44 were decreased. Therefore, KP regulated the OPN-CD44 pathway to inhibit atherosclerosis in the ApoE-deficient mouse aorta.

In addition, elevated plasma low-density lipoprotein (LDL) cholesterol levels were identified to be a risk factor for atherosclerosis and coronary heart disease (132). Ochiai et al (128) demonstrated that flavonoids stimulate the activity of Sp1 by phosphorylating Thr-453 and Thr-739 on ERK1/2, thereby increasing the DNA binding of Sp1 to the promoter region of the low-density lipoprotein receptor gene.

Che et al (133) also reported that KP alleviated oxidized (ox)-LDL-induced apoptosis. KP increased the ratio of microtubule-associated protein 1 light chain $3 \alpha$ and beclin-1 levels in ox-LDL-induced human umbilical vein endothelial cells (HUVECs). Furthermore, the expression of phosphorylated (p-)Akt and p-mammalian target of rapamycin (p-mTOR) was downregulated. The effect of KP on cell viability and apoptosis was also reduced by insulin in ox-LDL-induced HUVECs. From these results, it may be concluded that $\mathrm{KP}$ attenuates ox-LDL-induced apoptosis by upregulating autophagy through the PI3K/Akt/mTOR signaling pathway in human endothelial cells.

$K P$ inhibits thrombosis and platelet activation. High-risk cerebrovascular disease is mainly caused by abnormal blood vessel thrombosis after hemostasis, which may include fibrinolytic system dysfunction caused by abnormal fibrinolytic factors, e.g. plasmin and plasminogen activator, and thrombosis induced by an imbalance of coagulation factors (134). A thrombus composed of an insoluble fibrin polymer is formed by activating thrombin, which in turn converts fibrinogen to fibrin and factor XIIIa (135). 
KP has been demonstrated to inhibit procoagulant activity and the interaction between fibrinogen and thrombin by inhibiting ERK, serine protease p38, JNK and Akt activation. In addition, platelet activation is a major event in acute vascular thrombosis. Therefore, another treatment strategy is to prevent enhanced platelet activation (136). ROS generated after collagen stimulation is associated with various platelet activation events, including phospholipase $\mathrm{C} \gamma 2$ activation, cytosolic calcium elevation, integrin- $\alpha$ and $-\beta$ activation and granule release (137). Wang et al (138) indicated that KP inhibits collagen-induced triphosphopyridine nucleotide oxidase activation and potently suppresses the tyrosine phosphorylation-based glycoprotein VI signaling pathway by preventing oxidative inactivation of $\mathrm{SH} 2$-containing phosphatase 2, and then attenuates collagen-induced platelet aggregation and platelet-dependent thrombosis.

$K P$ suppresses angiogenesis of human retinal endothelial cells (HRECs) under high-glucose conditions. Diabetic retinopathy (DR) is a common microvascular complication of diabetes, which is also the most likely cause of blindness in developed countries (139). Retinal neovascularization is seen as an essential factor in the pathogenesis of DR (140). VEGF may stimulate vasculogenesis and angiogenesis. In the aqueous humor of patients with DR and in endothelial cells exposed to high glucose, the levels of VEGF were determined to be increased $(141,142)$. It has been demonstrated that the expression of thrombospondin 1 and metallopeptidases with TSP type 1 motif (ADAM), which are endogenous inhibitors of angiogenesis, may have an important role in diabetes-associated retinal vascular homeostasis and vascular dysregulation (143).

Wu et al (144) reported that high glucose significantly promoted the proliferation, migration and tube formation of HRECs, which was antagonized by 10 and $30 \mathrm{mM} \mathrm{KP}$ in a dose-dependent manner. They indicated that the expression levels of TSP-1 and ADAM mRNA increased following treatment with $30 \mathrm{mM} \mathrm{KP}$, while TSP-1 and ADAM levels did not differ between high-glucose and normal $(5 \mathrm{mM})$ glucose conditions. Xu et al (145) also demonstrated that high glucose increased the mRNA expression levels of VEGF and placental growth factor (PGF), and that the concentration of secreted VEGF and PGF from HRECs increased. Chin et al (146) also indicated that KP significantly reduced VEGF-stimulated HUVEC proliferation. These results indicate that in VEGF-stimulated ECs, KP may exert angiogenic inhibition through regulation of VEGF/VEGF receptor 2 and its downstream signaling cascades (PI3K/AKT, MEK and ERK).

\section{KP protects heart function}

$K P$ protects against doxorubicin (DOX)-induced cardiotoxicity. DOX is an anthracycline and is one of the most widely used anti-tumor drugs with potent activity. However, it may induce cardiotoxicity, which may cause cardiomyopathy or even severe heart failure (147). The mechanism of DOX-induced cardiomyocyte apoptosis has been extensively studied (148) and apoptosis is thought to start with two typical signaling pathways, one intrinsic and one extrinsic (149). Xiao et al (149) suggested that KP may have a role in inhibiting tumor suppressor proteins, protects against DNA damage with p53-mediated mitochondria-dependent intrinsic apoptotic signaling and participates in the ERK-dependent MAPK signaling pathway.

KP protects against cardiac sinus node dysfunction (SND). The normal heartbeat begins with the sinus node cells in the right atrium (150). The electrical pulse in this conduction process is generated based on the $\mathrm{Ca}^{2+}$ signal transduction pathway (151). Calmodulin kinase II (CaMKII) is a key signaling molecule in pacing cardiomyocytes and regulates major $\mathrm{Ca}^{2+}$ homeostasis proteins (152). In addition, after its oxidation, overactivated CaMKII promotes cell death, which may lead to arrhythmias, heart failure and sudden death (153).

An and Kim (15) indicated that KP protects the sinus node from angiotensin II (Ang II)-induced SND. Their results suggested that Ang II induced caspase-3-activated apoptosis in sinus node cells, and reduced CaMKII oxidation and death of sinoatrial node cells; KP maintained normal impulse formation in the right atrium. These results suggest that KP may hold value in the prevention of SND in high-risk patients and protection of the sinoatrial node by inhibiting CaMKII oxidation.

KP attenuates cardiac hypertrophy. Cardiac hypertrophy is a common disease that causes heart dysfunction and various cardiovascular diseases as the size and shape of the heart change (154). The MAPK signaling pathway is frequently overactivated in pathological cardiac hypertrophy (155). When the MAPK signaling cascade is activated, its members phosphorylate various downstream signal targets, thereby enhancing cardiac hypertrophy (155).

Feng et al (156) indicated that KP significantly attenuated aortic banding-induced cardiac hypertrophy, which led to a decreased myocardial cell area and interstitial fibrosis. $\mathrm{KP}$ inhibited the activity of the apoptotic signal-regulating kinase 1 (ASK1)/JNK1/JNK2/p38 signaling pathway and the proliferation of $\mathrm{H} 9 \mathrm{c} 2$ cardiomyocytes. It may be concluded that KP is able to prevent cardiac hypertrophy, and it may exert its role through the regulation of the ASK1/MAPK signaling pathway and oxidative stress.

Another factor that induces cardiac hypertrophy may be Ang II (157) and the mechanism that promotes Ang II-induced cardiac fibrosis is EMT. Zeisberg et al (158) reported that the endothelocytes were transformed into fibroblasts by EMT during the development of myocardial fibrosis in mice. Liu et al (159) indicated that, although KP did not have a fundamental role, it reduced Ang II infusion or TGF- $\beta$-induced EMT, and inhibited the proliferation and activation of cardiac fibroblasts in vivo as well as in vitro.

KP attenuates myocardial I/R injury. Cardiovascular diseases are responsible for the majority of mortalities in the elderly and the most important presentation of cardiovascular disease is ischemia (160). Restoring the blood supply to the ischemic myocardium may reduce myocardial damage, but may also cause damage or even aggravate myocardial damage, known as I/R injury (161).

Suchal et al (162) demonstrated that the major cause of damage was the production of ROS and calcium overload (163). 
Recent evidence suggested that mitochondrial protection has an important role in guiding apoptosis (164). Khader et al (165) demonstrated that sirtuin 1 activation reduced oxidative stress and maintained mitochondrial function in different tissue and cell types after I/R.

Suchal et al (162) also indicated that KP attenuated myocardial I/R injury by reducing MAPK signaling-induced oxidative stress and inflammation. Guo et al (164) obtained a similar result, namely that KP protected cardiomyocytes by inhibiting the MAPK pathway, with the effects including a decrease in the production of ROS, maintenance of the mitochondrial membrane potential, inhibition of mitochondrial membrane transition (mPTP) opening and reduction of cytochrome $\mathrm{C}$ release.

In addition, Zhou et al (166) suggested that glycogen synthase kinase-3 (GSK-3) $\beta$ inhibition delays or suppresses mPTP opening and inhibits the release of cytochrome C. They indicated that KP decreased apoptosis induced by I/R injury via GSK-3 $\beta$ inhibition. KP or thiadiazolidinone- 8 increased the level of GSK-3 $\beta$ phosphorylation and reduced the release of cytochrome $\mathrm{C}$ compared with the control and I/R groups.

\section{KP protects the cranial nerve}

Protective effect of KP in neurodegenerative diseases. The pathophysiology of neurodegenerative diseases is complex and may be partially characterized by oxidative stress, which is generally thought to have a key role in nerve damage (167). Previous studies have indicated that ROS is involved in neurodegenerative diseases and that they are produced in high concentrations due to oxidative metabolism in the brain (168). Under normal conditions, the generation and elimination of ROS are in a dynamic balance (169). However, if the balance is destroyed, the level of ROS increases due to the decreased activity of anti-oxidant enzymes, which impairs the brain function, particularly in the hippocampus.

Lei et al (167) indicated that KP obviously reduces cognitive impairment via upregulating the expression of proteins in the ERK1/2-cAMP-responsive element-binding protein (CREB) signaling pathway; KP may also enhance $\mathrm{Na}^{+} / \mathrm{K}^{+}$-ATPase activity and reduce hippocampal oxidative stress. In addition, an increase in the number of hydroxyl groups in the flavonol $\mathrm{B}$ ring also contributes to the upregulation of the expression of proteins from the ERK1/2-CREB signaling pathway in the hippocampus of mice with D-gal-induced cognitive impairment.

$K P$ has anti-depressant activities. Chronic stress is thought to be a risk factor for psychosomatic and psychiatric illnesses, including anxiety and depressive disorders (170). Depression is the second most common chronic condition in clinical medicine (171) and it is predicted that by 2020, depression will become the second leading cause of premature death or disability worldwide.

Park et al (172) used the tail suspension test (TST), the forced swimming test (FST) and the rota-rod test in mice who were stressed due to the chronic use of restraints or immobilization to measure the anti-depressant activities of KP. Mice in the experiment were orally administered KP or quercetin at a dose of $30 \mathrm{mg} / \mathrm{kg} / \mathrm{day}$ for 14 days while being tested. The final experimental results suggested that KP or quercetin obviously reduced the immobility time in the TST and FST, indicating that flavonoids have potent anti-depressant effects.

$K P$ has neuroprotective effects in Parkinson's disease (PD). $\mathrm{PD}$ is the second most common disorder of the central nervous system (173). Its pathological features are the loss of dopaminergic neurons and the formation of cytoplasmic inclusions in the substantia nigra (SN). When PD is present, $\sim 80 \%$ of striatal dopamine is lost and damage to the terminal region may preempt the loss of cell bodies in SN (174).

Han et al (175) hypothesized that inflammasomes are associated with immune homeostasis and their dysregulation leads to neurodegenerative disorders. The NLR family pyrin domain containing 3 (NLRP3) inflammasome is involved in PD. KP inhibits NLRP3 inflammasome activation, leading to reduced NLRP3 protein expression and deactivation of the NLRP3 inflammasome in order to promote macroautophagy/ autophagy in microglia.

$\mathrm{Li}$ and $\mathrm{Pu}$ (176) indicated that pre-intake of KP markedly improved 1-methyl-4-phenyl-1,2,3,6-tetrahydropyridine (MPTP)-induced dopamine and dihydroxy-phenyl acetic acid (DOPAC) depletion in the striatum, and also reduced the DOPAC/dopamine ratio and the MPTP-induced loss of tyrosine hydroxylase-positive neurons in mouse SN. KP has a neuroprotective effect in mice with MPTP-induced PD, which may contribute to its anti-oxidant capacity to scavenge free radicals and lead to the survival of more dopamine neurons.

In previous studies, KP 3-O-rutinoside and anhydrosafflor yellow B, as the compounds isolated from SSFE, a standardized safflower flavonoid extract, have been demonstrated to reduce the levels of ROS, which are induced by hydrogen peroxide and restore tyrosine hydroxylase activity in PC12 cells (177). Ren et al (178) indicated that KP 3-O-rutinoside and dehydrin flavonoid B inhibited microtubule instability and reduced the cell volume. In addition, SSFE, in the form of pills, may inhibit astrocyte proliferation and improve the neurological behavior in a 6-hydroxydopamine (6-OHDA)-induced PD rat model. In a study using a magnetic resonance imaging-based, tracer-based approach, 6-OHDA was indicated to alter diffusion parameters of endothelial cells, including reduced bowing and clearance rate constants and increased elimination half-life of the tracer in the SN with 6-OHDA-induced lesions. These results indicated that flavonoids may be potential anti-PD medicines.

$K P$ prevents Alzheimer's disease (AD). Studies have indicated that the abnormal production of various proteins and high concentrations of glutamate may lead to excessive ROS production in cells, resulting in neurotoxicity and neuronal death (179). Yang et al (180) examined the neuroprotective effects of KP in glutamate-treated HT22 hippocampal neuronal cells. Lactate dehydrogenase assays and fluorescein-5-isothiocyanate-connexin V/propidium iodide double staining procedures were subsequently used to confirm the protective effect of KP on HT22 cells. These results also indicated that KP protects nerves by regulating the expression levels of apoptosis-associated proteins, including Bcl-2, Bid, apoptosis-inducing factor and MAPK.

AD is characterized by the accumulation and deposition of $\beta$-amyloid peptides, leading to progressive neuronal damage 
and cell loss. Among several hypotheses, oxidative stress may be a mechanism that leads to neurodegeneration. To date, there is no cure for $\mathrm{AD}$, but the use of natural anti-oxidants may delay the pathogenesis of the disease. These results suggest that KP may serve as a useful drug for the prevention and treatment of neurodegenerative diseases, including AD.

$K P$ inhibits ischemic stroke. Ischemic stroke is a clinical syndrome characterized by the rapid onset of neurological deficits, mostly caused by arterial occlusion. The brain is particularly susceptible to ischemic injury due to its high metabolic requirement (181).

It is reported that the process of ischemic brain injury may include LPS binding to TLR4, causing microglia to be activated by TLR 2 and TLR4, followed by release of pro-inflammatory factors from the TLR4/MyD88 signaling pathway and produce further damage (182). The function of blood-brain barrier (BBB) is to keep harmful substances in the blood from being transported into the brain. One of the most prominent causes of brain damage is BBB decomposition and neuroinflammation, and therefore, the key to protecting the nerve is the maintenance of anti-neuritis processes and BBB integrity (183).

Cheng et al (184) indicated that KP reduces the production of various pro-inflammatory and inflammatory proteins in brain tissue, including IL-1, iNOS, COX-2, TNF- $\alpha$, MCP-1 and IL-1 $\beta$. In addition, KP protected BBB integrity in the mouse brain and increased BBB-associated proteins (occludin-1, claudin-1 and connexin43). KP also significantly reduced HMGB1 levels and inhibited the expression of components of the TLR4/MyD88 inflammatory pathway at the transcriptional and translational levels.

Mitochondrial dysfunction is a factor associated with ischemic stroke. Wu et al (185) indicated that KP protected neurons from ischemic injury by inhibiting mitochondrial fission and maintaining mitochondrial hexokinase II (HK-II). KP promoted mitochondrial binding of HK-II by inhibiting actin-related protein 1 (Drp1) activation, which was dependent on Akt. Furthermore, they demonstrated that KP enhanced autophagy during oxygen and glucose deprivation. In vivo, oral administration of KP resulted in a reduced infarct volume in mice after I/R injury and exerted an effect similar to mitochondrial protection in the infarcted area, indicating an association between succinic acid accumulation and I/R injury-induced nerve meta-mitochondrial dysfunction, and suggesting that modulation of Drp1 phosphorylation is a potential strategy for protecting neuronal mitochondrial integrity and treating ischemic stroke.

\section{KP for fibroproliferative disorders}

HPS is a complex dermal fibroproliferative disorder (185), which generally occurs after burns, trauma or surgery, and is linked to excessive wound healing (186). In HPS, myofibroblasts cause scar contraction, which may cause dysfunction of the affected body parts and even disability (187). Therefore, the major cause of HPS formation is excessive development and hyperfunction of scar-forming fibroblasts (188).

Li et al (189) discovered that KP obviously inhibited HPS formation in a mechanically induced mouse model, and the biological activity of KP was induced by selective binding of $\mathrm{KP}$ to TGF- $\beta 1$. Kinase binding assays indicated competitive binding of KP to the ATP binding site of TGF- $\beta 1$. Western blot analysis further revealed that KP caused downregulation of SMAD2 and -3 phosphorylation in a dose-dependent manner. The bioactivity of KP, which resulted from the inhibition of TGF- $\beta 1 /$ SMADs signaling, was induced by the selective binding of KP to TGF- $\beta$ receptor type I. These results suggested that KP may be a promising treatment for fibro-proliferative diseases including HPS, and even liver fibrosis, pulmonary fibrosis and myocardial fibrosis, which are highly associated with the TGF- $\beta 1 /$ SMADs signaling pathway.

\section{Conclusion}

Flavonoids have been widely recognized for their effective anti-inflammatory and anti-oxidant properties. The major signaling pathways via which KP exerts its effects in various diseases are summarized in Fig. 2.

The flavonoid ring structure is a structure necessary for mutagenic activity, and this activity may depend on characteristics including the degree of hydroxylation structural features and the production of ROS (190). It may be hypothesized that the major role of KP is to regulate the expression of genes involved in inflammation, including the inhibition of transcription factors. MAPK, PKC, PI3K, Janus kinase signaling and transcriptional activator pathways are involved in the development of inflammation. These kinases have roles in the regulation of the expression and activity of transcription factors, including NF- $\kappa$ B and AP-1 (191). PI3K is an important mediator in the inflammatory signaling cascade, and KP and 8-prenylkaempferol treatment have been indicated to inhibit PI3K and Akt phosphorylation (192). In conclusion, KP has therapeutic effects on inflammation-associated diseases, including allergies, arthritis, diabetes, cardiovascular diseases, cancers and neurological regression by inhibiting protein kinases and transcription factors.

Although it has been reported that KP has the highest anti-proliferative effect on the hepatoblastoma cell line, the colon cancer cell line and the melanoma cell line (193), there is controversy regarding the anti-cancer effect. Studies have indicated that KP represents a double-edged sword in terms of exhibiting cytotoxic and cytoprotective effects. Noroozi et al (194) reported that KP decreased oxidative DNA damage in isolated human lymphocytes and increased cell survival in HT-22 neuronal cells under oxidative stress. However, in the study by Bestwick et al (195), KP was demonstrated to reduce ROS levels in HL-60 cells at low doses of KP, but the occurrence of single strand breaks was KP concentration-dependent. Thus, despite low initial ROS levels, $\mathrm{KP}$ has an adverse effect on DNA integrity. Furthermore, KP-induced DNA damage is highly localized and specific. The cause of DNA damage may be highly localized changes in ROS production. Sahu and Gray (196) hypothesized that HO formation close to DNA molecules may be the cause of chain breaks, but this is also affected by the environment.

To date, flavonoids have been reported as typical cytotoxic chemotherapeutic agents to treat acute myeloid leukemia by causing DNA damage, which may make abnormal cells more susceptible to therapeutic agents due to an environment with 


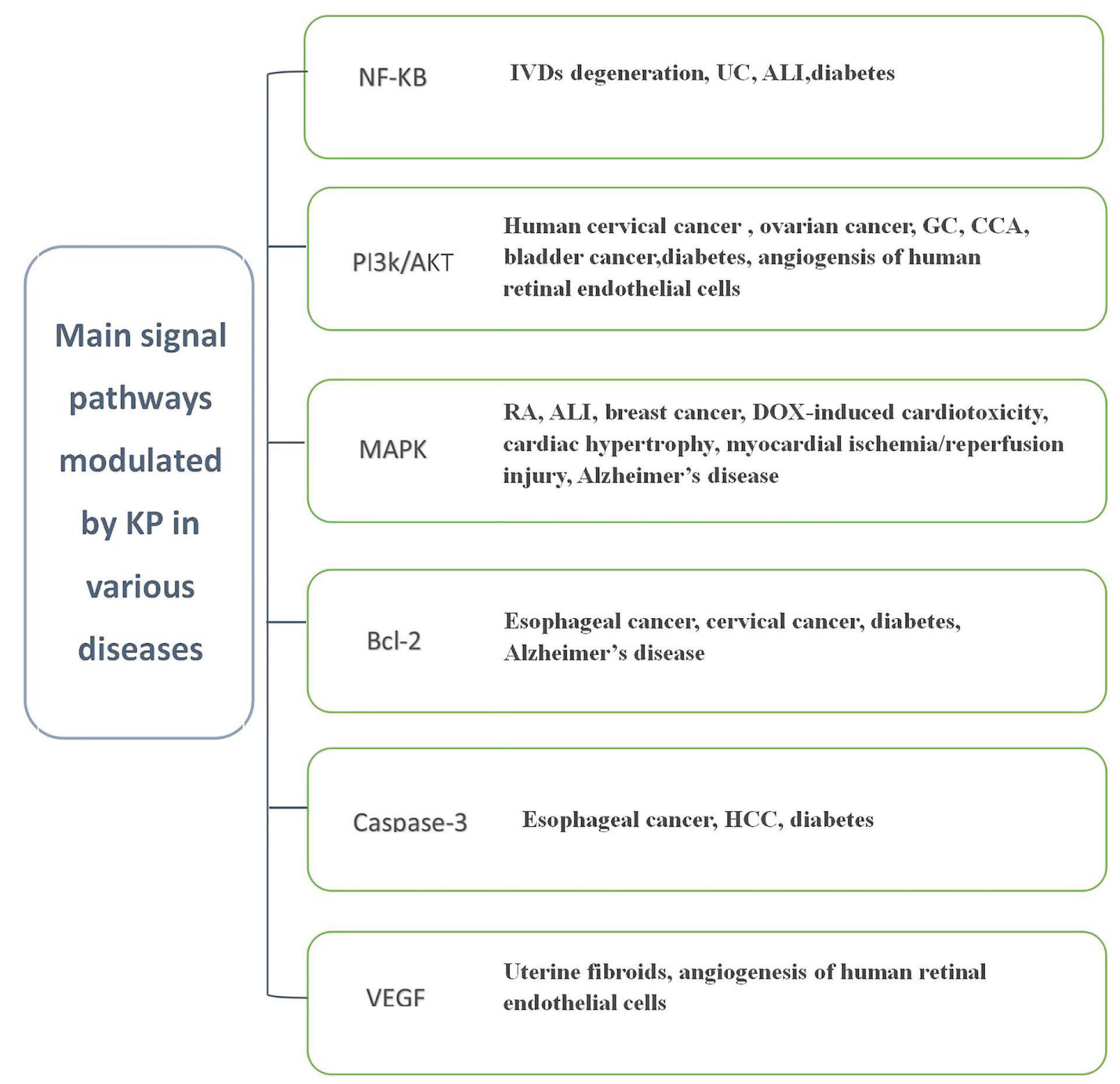

Figure 2. Main signaling pathways modulated by KP in various diseases. HCC, hepatocellular carcinoma; VEGF, vascular endothelial growth factor; IVD, intervertebral disc; UC, ulcerative colitis; ALI, acute lung injury; GC, gastric cancer; CCA, cholangiocarcinoma; MAPK, mitogen-activated protein kinase; RA, rheumatoid arthritis; DOX, doxorubicin; KP, kaempferol.

less oxidative stress (197). Das et al (198) suggested that the flavonoid with the highest affinity for circulating tumor DNA (ct-DNA) is quercetin, followed by myricetin, luteolin and KP; the number and position of - $\mathrm{OH}$ moieties influences the binding efficacies of flavonoids to ct-DNA. Therefore, the combination of quercetin and myricetin may cause higher DNA damage, which can be served as a potential anti-cancer agent.

The genotoxicity of KP is mainly due to its pro-oxidative activity in vitro. Cos et al (199) introduced an anti-oxidant selectivity index (ASI), which is the maximal non-toxic dose divided by the $\mathrm{IC}_{50}$ value, used to assess the toxicity of flavonoids. If the ASI of flavonoids is $>100$, it may be considered safe and to possess a good anti-oxidant activity profile, but the ASI requires to be further investigated.

Furthermore, KP has poor absorption, particularly regarding oral bioavailability, which is likely due to the limited solubility of flavonoids in water (200). However, the bioavailability of KP may be increased if combined with different anti-cancer drugs (5). Regarding its poor absorption, considerations for improving the solubility and bioavailability of KP may be the use of nanocarriers, which increase absorption and enhance anti-free radical stability during consumption and storage of food compounds (6). Qian et al (201) developed a $\mathrm{KP}$ nanosuspension, which is produced using high-pressure homogenization technology, to improve pharmacokinetics and absolute bioavailability. Resende et al (202) used poloxamer 407 to prepare a solid dispersion of KP, which ultimately improved the problem of poor water solubility. It has been demonstrated that mechanochemically synthesized complexes of polysaccharides and oligosaccharides can enhance bioavailability, and the supramolecular complexes are more stable and soluble than the individual components (203). Xu et al (204) indicated that the combination of KP with polysaccharide arabinogalactan and disodium glycyrrhizinate improved the solubility and bioavailability of KP, which may be used as a promising treatment for diabetes.

In addition, whether KP exerts toxicity in a dietary environment remains elusive, and since $\mathrm{KP}$ is not the sole active component, it is necessary to consider other active polyphenols in the diet. Although there is little evidence that a natural flavonoid-rich diet is harmful in the body, it may be unwise to propose an enhanced supplemental intake. High doses of KP 
may have side effects. For instance, studies have shown that flavonoid compounds are markedly inhibited (3). H-folic acid uptake, means patients who are deficient in iron and/or folic acid may exhibit abnormal side effects after using KP, as the consumption of KP reduces the bioavailability of iron and/or reduces the level of folic acid in the cells (205). KP could be incorporated into potential nanoparticles to achieve high targeting efficacy against folate-overexpressing cancerous cells while limiting the potential effects on normal cells (206).

In conclusion, KP inhibits protein kinases and transcription factors due to its anti-inflammatory and antioxidant properties. However, while protecting cells, cytotoxicity is also exhibited, which is associated with ROS production by the concentration of KP. Therefore, it is necessary to introduce a standard for producing cytotoxicity. Additionally, the oral bioavailability of $\mathrm{KP}$ is poor, and most of its current uses are as nanocarriers. The combination of polysaccharides and oligosaccharide complexes can improve bioavailability. In terms of diet, whether KP is toxic requires further investigation as a high intake of KP may cause adverse side effects. Patients with iron and/or folic acid may exhibit abnormal side effects after using KP.

\section{Acknowledgements}

Not applicable.

\section{Funding}

The present study was supported by the National Natural Science Foundation of China (grant nos. 81620108030 and 81873076 ), the Key project of Shanghai 3-year plan (grant no. ZY2018-2020-CCCX-2002-01), the Shanghai Rising-Star Project (grant no. 15QA1403500) and the Shanghai Talents development fund Project (grant no. 2017090) and the Innovation Project for Undergraduates of Shanghai University of Traditional Chinese Medicine (grant. no. 2017SHUTCM223).

\section{Availability of data and materials}

Not applicable.

\section{Authors' contributions}

TW and GJ designed the present study. JR and TW prepared and wrote the manuscript. YL, YQ and BC performed a literature search and selected the studies to be included. TW and GJ revised the manuscript. All authors approved the final version of the article.

\section{Ethics approval and consent to participate}

Not applicable.

\section{Patient consent for publication}

Not applicable.

\section{Competing interests}

The authors declare that they have no competing interests.

\section{References}

1. Devi KP, Malar DS, Nabavi SF, Sureda A, Xiao J, Nabavi SM and Daglia M: Kaempferol and inflammation: From chemistry to medicine. Pharmacol Res 99: 1-10, 2015.

2. Tsao R: Chemistry and biochemistry of dietary polyphenols. Nutrients 2: 1231-1246, 2010.

3. Calderón-Montaño JM, Burgos-Morón E, Pérez-Guerrero C and López-Lázaro M: A review on the dietary flavonoid kaempferol. Mini Rev Med Chem 11: 298-344, 2011.

4. Park JS, Rho HS, Kim DH and Chang IS: Enzymatic preparation of kaempferol from green tea seed and its antioxidant activity. J Agric Food Chem 54: 2951-2956, 2006.

5. Chen AY and Chen YC: A review of the dietary flavonoid, kaempferol on human health and cancer chemoprevention. Food Chem 138: 2099-2107, 2013.

6. Yadav KS and Sawant KK: Modified nanoprecipitation method for preparation of cytarabine-loaded PLGA nanoparticles. AAPS PharmSciTech 11: 1456-1465, 2010.

7. Hegde A and Bhatia M: Hydrogen sulfide in inflammation: Friend or foe? Inflamm Allergy Drug Targets 10: 118-122, 2011.

8. Folkerts G, Kloek J, Muijsers RB and Nijkamp FP: Reactive nitrogen and oxygen species in airway inflammation. Eur J Pharmacol 429: 251-262, 2001.

9. Lin MK, Yu YL, Chen KC, Chang WT, Lee MS, Yang MJ, Cheng HC, Liu CH, Chen DzC and Chu CL: Kaempferol from Semen cuscutae attenuates the immune function of dendritic cells. Immunobiology 216: 1103-1109, 2011.

10. Nosikova YS, Santerre JP, Grynpas M, Gibson G and Kandel RA: Characterization of the annulus fibrosus-vertebral body interface: Identification of new structural features. J Anat 221: 577-589, 2012.

11. Zhu J, Tang H, Zhang Z, Zhang Y, Qiu C, Zhang L, Huang P and Li F: Kaempferol slows intervertebral disc degeneration by modifying LPS-induced osteogenesis/adipogenesis imbalance and inflammation response in BMSCs. Int Immunopharmacol 43: 236-242, 2017.

12. Silverwood V, Blagojevic-Bucknall M, Jinks C, Jordan JL, Protheroe $\mathrm{J}$ and Jordan KP: Current evidence on risk factors for knee osteoarthritis in older adults: A systematic review and meta-analysis. Osteoarthritis Cartilage 23: 507-515, 2015.

13. Asanbaeva A, Tam J, Schumacher BL, Klisch SM, Masuda K and Sah RL: Articular cartilage tensile integrity: Modulation by matrix depletion is maturation-dependent. Arch Biochem Biophys 474: 175-182, 2008.

14. Lawrence RC, Felson DT, Lawrence RC, Gabriel S, Hirsch R, Kwoh CK, Liang MH, Kremers HM, Mayes MD, Merkel PA, et al: Estimates of the prevalence of arthritis and other rheumatic conditions in the United States. Part II. Arthritis Rheum 58: 15-25, 2008.

15. Liu-Bryan R and Terkeltaub R: Emerging regulators of the inflammatory process in osteoarthritis. Nat Rev Rheumatol 11: 35-44, 2015.

16. Abramson SB: Osteoarthritis and nitric oxide. Osteoarthritis Cartilage 16 (Suppl 2): S15-S20, 2008.

17. Honghai Z, Zhang T, Xia C, Shi L, Wang S, Zheng X, Hu T and Zhang B: Berberine ameliorates cartilage degeneration in interleukin-1 $\beta$-stimulated rat chondrocytes and in a rat model of osteoarthritis via Akt signalling. J Cell Mol Med 18: 283-292, 2014.

18. Park MY, Ji GE and Sung MK: Dietary kaempferol suppresses inflammation of dextran sulfate sodium-induced colitis in mice. Dig Dis Sci 57: 355-363, 2012.

19. Sordillo LM and Streicher KL: Mammary gland immunity and mastitis susceptibility. J Mammary Gland Biol Neoplasia 7: 135-146, 2002.

20. Xiao HB, Sui GG, Lu XY and Sun ZL: Kaempferol modulates Angiopoietin-like protein 2 expression to lessen the mastitis in mice. Pharmacol Rep 70: 439-445, 2018.

21. Alam J, Jantan I and Bukhari SNA: Rheumatoid arthritis: Recent advances on its etiology, role of cytokines and pharmacotherapy. Biomed Pharmacother 92: 615-633, 2017.

22. Pan D, Li N, Liu Y, Xu Q, Liu Q, You Y, Wei Z, Jiang Y, Liu M, Guo T, et al: Kaempferol inhibits the migration and invasion of rheumatoid arthritis fibroblast-like synoviocytes by blocking activation of the MAPK pathway. Int Immunopharmacol 55: 174-182, 2018.

23. Lee CJ, Moon SJ, Jeong JH, Lee S, Lee MH, Yoo SM, Lee HS, Kang HC, Lee JY, Lee WS, et al: Kaempferol targeting on the fibroblast growth factor receptor 3-ribosomal S6 kinase 2 signaling axis prevents the development of rheumatoid arthritis. Cell Death Dis 9: 401, 2018. 
24. Gill SE, Rohan M and Mehta S: Role of pulmonary microvascular endothelial cell apoptosis in murine sepsis-induced lung injury in vivo. Respir Res 16: 109, 2015.

25. Villar J, Blanco J, Añón JM, Santos-Bouza A, Blanch L, Ambrós A, Gandía F, Carriedo D, Mosteiro F, Basaldúa S, et al: The ALIEN study: Incidence and outcome of acute respiratory distress syndrome in the era of lung protective ventilation. Intensive Care Med 37: 1932-1941, 2011.

26. Matthay MA and Zimmerman GA: Acute lung injury and the acute respiratory distress syndrome: Four decades of inquiry into pathogenesis and rational management. Am J Respir Cell Mol Biol 33: 319-327, 2005.

27. Zhang R, Ai X, Duan Y, Xue M, He W, Wang C, Xu T, Xu M, Liu B, Li C, et al: Kaempferol ameliorates H9N2 swine influenza virus-induced acute lung injury by inactivation of TLR4/MyD88-mediated NF- $\mathrm{BB}$ and MAPK signaling pathways. Biomed. Pharmacother 89: 660-672, 2017.

28. Rabha DJ, Singh TU, Rungsung S, Kumar T, Parida S, Lingaraju MC, Paul A, Sahoo M and Kumar D: Kaempferol attenuates acute lung injury in caecal ligation and puncture model of sepsis in mice. Exp Lung Res 44: 63-78, 2018.

29. Chen X, Yang X, Liu T, Guan M, Feng X, Dong W, Chu X, Liu J, Tian X, Ci X, et al: Kaempferol regulates MAPKs and NF-кB signaling pathways to attenuate LPS-induced acute lung injury in mice. Int Immunopharmacol 14: 209-216, 2012.

30. Gong JH, Shin D, Han SY, Kim JL and Kang YH: Kaempferol suppresses eosionphil infiltration and airway inflammation in airway epithelial cells and in mice with allergic asthma. J Nutr 142: 47-56, 2012.

31. Banerjee R and Puniyani RR: Exogenous surfactant therapy and mucus rheology in chronic obstructive airway diseases. J Biomater Appl 14: 243-272, 2000.

32. Davies DE: The role of the epithelium in airway remodeling in asthma. Proc Am Thorac Soc 6: 678-682, 2009.

33. Erjefält JS: The airway epithelium as regulator of inflammation patterns in asthma. Clin Respir J 4 (Suppl 1): S9-S14, 2010.

34. Kim SR and Lee YC: Endoplasmic reticulum stress and the related signaling networks in severe asthma. Allergy Asthma Immunol Res 7: 106-117, 2015.

35. Makhija L, Krishnan V, Rehman R, Chakraborty S, Maity S, Mabalirajan U, Chakraborty K, Ghosh B and Agrawal A: Chemical chaperones mitigate experimental asthma by attenuating endoplasmic reticulum stress. Am J Respir Cell Mol Biol 50: 923-931, 2014.

36. Park SH, Gong JH, Choi YJ, Kang MK, Kim YH and Kang YH: Kaempferol inhibits endoplasmic reticulum stress-associated mucus hypersecretion in airway epithelial cells and ovalbumin-sensitized mice. PLoS One 10: e0143526, 2015.

37. Lopez-Basave HN, Morales-Vásquez F, Ruiz-Molina JM, Namendys-Silva SA, Vela-Sarmiento I, Ruan JM, Rosciano AE, Calderillo-Ruiz G, Díaz-Romero C, Herrera-Gómez A and Meneses-García AA: Gastric cancer in young people under 30 years of age: Worse prognosis, or delay in diagnosis? Cancer Manag Res 5: 31-36, 2013.

38. Li WF, Hao DJ, Fan T, Huang HM, Yao H and Niu XF: Protective effect of chelerythrine against ethanol-induced gastric ulcer in mice. Chem Biol Interact 208: 18-27, 2014.

39. Bae S, Kim N, Kang JM, Kim DS, Kim KM, Cho YK, Kim JH, Jung SW and Shim KN: Incidence and 30-day mortality of peptic ulcer bleeding in Korea. Eur J Gastroenterol Hepatol 24: 675-682, 2012.

40. Ribeiro AR, Diniz PB, Pinheiro MS, Albuquerque-Júnior RL and Thomazzi SM: Gastroprotective effects of thymol on acute and chronic ulcers in rats: The role of prostaglandins, ATP-sensitive $\mathrm{K}(+)$ channels, and gastric mucus secretion. Chem Biol Interact 244: 121-128, 2016.

41. Ateufack G, Domgnim Mokam EC, Mbiantcha M, Dongmo Feudjio RB, David N and Kamanyi A: Gastroprotective and ulcer healing effects of Piptadeniastrum Africanum on experimentally induced gastric ulcers in rats. BMC Complement Altern Med 15: 214, 2015.

42. Almasaudi SB, Abbas AT, Al-Hindi RR, El-Shitany NA, Abdel-Dayem UA, Ali SS, Saleh RM, Al Jaouni SK, Kamal MA and Harakeh SM: Manuka honey exerts antioxidant and anti-inflammatory activities that promote healing of acetic acid-induced gastric ulcer in rats. Evid Based Complement Alternat Med 2017: 5413917, 2017.

43. Niv Y and Banić M: Gastric barrier function and toxic damage. Dig Dis 32: 235-242, 2014.
44. Hajrezaie M, Golbabapour S, Hassandarvish P, Gwaram NS, A Hadi AH, Mohd Ali H, Majid N and Abdulla MA: Acute toxicity and gastroprotection studies of a new schiff base derived copper (II) complex against ethanol-induced acute gastric lesions in rats. PLoS One 7: e51537, 2012.

45. Li Q, Hu X, Xuan Y, Ying J, Fei Y, Rong J, Zhang Y, Zhang J, Liu C and Liu Z: Kaempferol protects ethanol-induced gastric ulcers in mice via pro-inflammatory cytokines and NO. Acta Biochim Biophys Sin (Shanghai) 50: 246-253, 2018.

46. Arif H, Sohail A, Farhan M, Rehman AA, Ahmad A and Hadi SM: Flavonoids-induced redox cycling of copper ions leads to generation of reactive oxygen species: A potential role in cancer chemoprevention. Int J Biol Macromol 106: 569-578, 2018.

47. Bandla S, Pennathur A, Luketich JD, Beer DG, Lin L, Bass AJ, Godfrey TE and Litle VR: Comparative genomics of esophageal adenocarcinoma and squamous cell carcinoma. Ann Thorac Surg 93: 1101-1106, 2012.

48. Pohl $\mathrm{H}$ and Welch HG: The role of overdiagnosis and reclassification in the marked increase of esophageal adenocarcinoma incidence. J Natl Cancer Inst 97: 142-146, 2005.

49. Yao S, Wang X, Li C, Zhao T, Jin H and Fang W: Kaempferol inhibits cell proliferation and glycolysis in esophagus squamous cell carcinoma via targeting EGFR signaling pathway. Tumour Biol 37: 10247-10256, 2016.

50. Zhang Q, Zhao XH and Wang ZJ: Flavones and flavonols exert cytotoxic effects on a human oesophageal adenocarcinoma cell line (OE33) by causing G2/M arrest and inducing apoptosis. Food Chem Toxicol 46: 2042-2053, 2008.

51. Diantini A, Subarnas A, Lestari K, Halimah E, Susilawati Y, Supriyatna, Julaeha E, Achmad TH, Suradji EW, Yamazaki C, et al: Kaempferol-3-O-rhamnoside isolated from the leaves of Schima wallichii Korth. inhibits MCF-7 breast cancer cell proliferation through activation of the caspase cascade pathway. Oncol Lett 3: 1069-1072, 2012.

52. Kim SH, Hwang KA and Choi KC: Treatment with kaempferol suppresses breast cancer cell growth caused by estrogen and triclosan in cellular and xenograft breast cancer models. J Nutr Biochem 28: 70-82, 2016.

53. Ren W, Qiao Z, Wang H, Zhu L and Zhang L: Flavonoids: Promising anticancer agents. Med Res Rev 23: 519-534, 2003.

54. Konopleva M, Zhao S, Xie Z, Segall H, Younes A, Claxton DF, Estrov Z, Kornblau SM and Andreeff M: Apoptosis. Molecules and mechanisms. Adv Exp Med Biol 457: 217-236, 1999.

55. Li S, Yan T, Deng R, Jiang X, Xiong H, Wang Y, Yu Q, Wang X, Chen $\mathrm{C}$ and Zhu Y: Low dose of kaempferol suppresses the migration and invasion of triple-negative breast cancer cells by downregulating the activities of RhoA and Racl. Onco Targets Ther 10: 4809-4819, 2017.

56. Yi X, Zuo J, Tan C, Xian S, Luo C, Chen S, Yu L and Luo Y: Kaempferol, a flavonoid compound from induced apoptosis and growth inhibition in MCF-7 breast cancer cell. Afr J Tradit Complement Altern Med 13: 210-215, 2016.

57. Zhu L and Xue L: Kaempferol suppresses proliferation and induces cell cycle arrest, apoptosis, and DNA damage in breast cancer cells. Oncol Res 27: 629-634, 2019.

58. Bray F, Ferlay J, Soerjomataram I, Siegel RL, Torre LA and Jemal A: Global cancer statistics 2018: GLOBOCAN estimates of incidence and mortality worldwide for 36 cancers in 185 countries. CA Cancer J Clin 68: 394-424, 2018.

59. Kashafi E, Moradzadeh M, Mohamadkhani A and Erfanian S: Kaempferol increases apoptosis in human cervical cancer HeLa cells via PI3K/AKT and telomerase pathways. Biomed Pharmacother 89: 573-577, 2017.

60. Guo H, Ren F, Zhang L, Zhang X, Yang R, Xie B, Li Z, Hu Z, Duan $Z$ and Zhang J: Kaempferol induces apoptosis in HepG2 cells via activation of the endoplasmic reticulum stress pathway. Mol Med Rep 13: 2791-2800, 2016.

61. Semenza GL: Defining the role of hypoxia-inducible factor 1 in cancer biology and therapeutics. Oncogene 29: 625-634, 2010.

62. Calvisi DF, Ladu S, Gorden A, Farina M, Conner EA, Lee JS, Factor VM and Thorgeirsson SS: Ubiquitous activation of Ras and Jak/Stat pathways in human HCC. Gastroenterology 130: 1117-1128, 2006.

63. Bruix J and Llovet JM: Major achievements in hepatocellular carcinoma. Lancet 373: 614-616, 2009.

64. Mylonis I, Lakka A, Tsakalof A and Simos G: The dietary flavonoid kaempferol effectively inhibits HIF-1 activity and hepatoma cancer cell viability under hypoxic conditions. Biochem Biophys Res Commun 398: 74-78, 2010. 
65. Seydi E, Salimi A, Rasekh HR, Mohsenifar Z and Pourahmad J: Selective cytotoxicity of luteolin and kaempferol on cancerous hepatocytes obtained from rat model of hepatocellular carcinoma: Involvement of ROS-mediated mitochondrial targeting. Nutr Cancer 70: 594-604, 2018.

66. Luo H, Rankin GO, Li Z, Depriest L and Chen YC: Kaempferol induces apoptosis in ovarian cancer cells through activating p53 in the intrinsic pathway. Food Chem 128: 513-519, 2011.

67. Mellier G, Huang S, Shenoy K and Pervaiz S: TRAILing death in cancer. Mol Aspects Med 31: 93-112, 2010.

68. Inoue T, Shiraki K, Fuke H, Yamanaka Y, Miyashita K, Yamaguchi Y, Yamamoto N, Ito K, Sugimoto K and Nakano T: Proteasome inhibition sensitizes hepatocellular carcinoma cells to TRAIL by suppressing caspase inhibitors and AKT pathway. Anticancer Drugs 17: 261-268, 2006.

69. Zhao Y, Tian B, Wang Y and Ding H: Kaempferol sensitizes human ovarian cancer cells-OVCAR-3 and SKOV-3 to tumor necrosis factor-related apoptosis-inducing ligand (TRAIL)-induced apoptosis via JNK/ERK-CHOP pathway and Up-regulation of death receptors 4 and 5. Med Sci Monit 23: 5096-5105, 2017.

70. Bartek $\mathbf{J}$ and Lukas J: Chk1 and Chk2 kinases in checkpoint control and cancer. Cancer Cell 3: 421-429, 2003.

71. Gao Y, Yin J, Rankin GO and Chen YC: Kaempferol induces G2/M cell cycle arrest via checkpoint Kinase 2 and promotes apoptosis via death receptors in human ovarian carcinoma A2780/CP70 cells. Molecules 23: pii: E1095, 2018.

72. Hundahl SA, Menck HR, Mansour EG and Winchester DP: The national cancer data base report on gastric carcinoma. Cancer 80: 2333-2341, 1997.

73. Alberts SR, Cervantes A and van de Velde CJ: Gastric cancer: Epidemiology, pathology and treatment. Ann Oncol 14 (Suppl 2): ii31-ii36, 2003.

74. Ajani JA: Evolving chemotherapy for advanced gastric cancer. Oncologist 10 (Suppl 3): S49-S58, 2005.

75. Roberts AB and Wakefield LM: The two faces of transforming growth factor beta in carcinogenesis. Proc Natl Acad Sci USA 100: 8621-8623, 2003.

76. DiMagno EP, Reber HA and Tempero MA: AGA technical review on the epidemiology, diagnosis, and treatment of pancreatic ductal adenocarcinoma. American Gastroenterological Association. Gastroenterology 117: 1464-1484, 1999.

77. Jo E, Park SJ, Choi YS, Jeon WK and Kim BC: Kaempferol suppresses transforming growth factor- $\beta 1$-induced Epithelial-to-Mesenchymal transition and migration of A549 lung cancer cells by inhibiting Akt1-mediated phosphorylation of Smad3 at threonine-179. Neoplasia 17: 525-537, 2015.

78. McCoyd M, Gruener G and Foy P: Neurologic aspects of lymphoma and leukemias. Handb Clin Neurol 120: 1027-1043, 2014

79. Wu LY, Lu HF, Chou YC, Shih YL, Bau DT, Chen JC, Hsu SC and Chung JG: Kaempferol induces DNA damage and inhibits DNA repair associated protein expressions in human promyelocytic leukemia HL-60 cells. Am J Chin Med 43: 365-382, 2015

80. Adams J and Nassiri M: Acute Promyelocytic leukemia: A review and discussion of variant translocations. Arch Pathol Lab Med 139: 1308-1313, 2015.

81. Moradzadeh M, Tabarraei A, Sadeghnia HR, Ghorbani A, Mohamadkhani A, Erfanian S and Sahebkar A: Kaempferol increases apoptosis in human acute promyelocytic leukemia cells and inhibits multidrug resistance genes. J Cell Biochem 119 2288-2297, 2018.

82. Song W, Dang Q, Xu D, Chen Y, Zhu G, Wu K, Zeng J, Long Q, Wang X, He D and Li L: Kaempferol induces cell cycle arrest and apoptosis in renal cell carcinoma through EGFR/p38 signaling. Oncol Rep 31: 1350-1356, 2014.

83. Qin Y, Cui W, Yang X and Tong B: Kaempferol inhibits the growth and metastasis of cholangiocarcinoma in vitro and in vivo. Acta Biochim Biophys Sin (Shanghai) 48: 238-245, 2016.

84. Neoptolemos JP, Dunn JA, Stocken DD, Almond J, Link K, Beger H, Bassi C, Falconi M, Pederzoli P, Dervenis C, et al: Adjuvant chemoradiotherapy and chemotherapy in resectable pancreatic cancer: A randomised controlled trial. Lancet 358: $1576-1585,2001$.

85. Brandes F, Schmidt K, Wagner C, Redekopf J, Schlitt HJ, Geissler EK and Lang SA: Targeting cMET with INC280 impairs tumour growth and improves efficacy of gemcitabine in a pancreatic cancer model. BMC Cancer 15: 71, 2015.

86. Di Renzo MF, Poulsom R, Olivero M, Comoglio PM and Lemoine NR: Expression of the Met/hepatocyte growth factor receptor in human pancreatic cancer. Cancer Res 55: 1129-1138, 1995 .
87. Lee J and Kim JH: Kaempferol inhibits pancreatic cancer cell growth and migration through the blockade of EGFR-related pathway in vitro. PLoS One 11: e0155264, 2016

88. Liang J, Wu L, Xiao H, Li N, Wang H, Cheng C, Bai R, Zhao Y and Zheng $\mathrm{H}$ : Use of myocardin in the classification of mesenchymal tumors of the uterus. Int J Gynecol Pathol 29: 55-62, 2010.

89. Li Y, Ding Z and Wu C: Mechanistic study of the inhibitory effect of kaempferol on uterine fibroids in vitro. Med Sci Monit 22: 4803-4808, 2016.

90. Qiu W, Lin J, Zhu Y, Zhang J, Zeng L, Su M and Tian Y: Kaempferol modulates DNA methylation and downregulates DNMT3B in bladder cancer. Cell Physiol Biochem 41: $1325-1335,2017$.

91. Azad N, Zahnow CA, Rudin CM and Baylin SB: The future of epigenetic therapy in solid tumours-lessons from the past. Nat Rev Clin Oncol 10: 256-266, 2013.

92. Maio M, Covre A, Fratta E, Di Giacomo AM, Taverna P, Natali PG, Coral S and Sigalotti L: Molecular pathways: At the crossroads of cancer epigenetics and immunotherapy. Clin Cancer Res 21: 4040-4047, 2015.

93. Lee SJ, Park SS, Kim WJ and Moon SK: Gleditsia sinensis thorn extract inhibits proliferation and TNF- $\alpha$-induced MMP-9 expression in vascular smooth muscle cells. Am J Chin Med 40: 373-386, 2012

94. Kansara M and Thomas DM: Molecular pathogenesis of osteosarcoma. DNA Cell Biol 26: 1-18, 2007.

95. Ottaviani G and Jaffe N: The epidemiology of osteosarcoma. Cancer Treat Res 152: 3-13, 2009.

96. Huang WW, Chiu YJ, Fan MJ, Lu HF, Yeh HF, Li KH, Chen PY, Chung JG and Yang JS: Kaempferol induced apoptosis via endoplasmic reticulum stress and mitochondria-dependent pathway in human osteosarcoma U-2 OS cells. Mol Nutr Food Res 54: 1585-1595, 2010.

97. Chen HJ, Lin CM, Lee CY, Shih NC, Peng SF, Tsuzuki M, Amagaya S, Huang WW and Yang JS: Kaempferol suppresses cell metastasis via inhibition of the ERK-p38-JNK and AP-1 signaling pathways in U-2 OS human osteosarcoma cells. Oncol Rep 30: 925-932, 2013.

98. Alter MJ: Epidemiology of viral hepatitis and HIV co-infection. J Hepatol 44 (1 Suppl): S6-S9, 2006.

99. Lee SS, Buters JT, Pineau T, Fernandez-Salguero P and Gonzalez FJ: Role of CYP2E1 in the hepatotoxicity of acetaminophen. J Biol Chem 271: 12063-12067, 1996.

100. Nicod L, Viollon C, Regnier A, Jacqueson A and Richert L: Rifampicin and isoniazid increase acetaminophen and isoniazid cytotoxicity in human HepG2 hepatoma cells. Hum Exp Toxicol 16: 28-34, 1997.

101. Shih TY, Young TH, Lee HS, Hsieh CB and Hu OY: Protective effects of kaempferol on isoniazid- and rifampicin-induced hepatotoxicity. AAPS J 15: 753-762, 2013.

102. Rudnicki M, Silveira MM, Pereira TV, Oliveira MR, Reginatto FH, Dal-Pizzol F and Moreira JC: Protective effects of Passiflora alata extract pretreatment on carbon tetrachloride induced oxidative damage in rats. Food Chem Toxicol 45: 656-661, 2007.

103. Sun F, Hamagawa E, Tsutsui C, Ono Y, Ogiri Y and Kojo S: Evaluation of oxidative stress during apoptosis and necrosis caused by carbon tetrachloride in rat liver. Biochim Biophys Acta 1535: 186-191, 2001.

104. Szymonik-Lesiuk S, Czechowska G, Stryjecka-Zimmer M, Słomka M, Madro A, Celiński K and Wielosz M: Catalase, superoxide dismutase, and glutathione peroxidase activities in various rat tissues after carbon tetrachloride intoxication. J Hepatobiliary Pancreat Surg 10: 309-315, 2003.

105. Wang Y, Tang $\mathrm{C}$ and Zhang H: Hepatoprotective effects of kaempferol 3-O-rutinoside and kaempferol 3-O-glucoside from Carthamus tinctorius $\mathrm{L}$. on $\mathrm{CCl}_{4}$-induced oxidative liver injury in mice. J Food Drug Anal 23: 310-317, 2015.

106. O'Shea RS, Dasarathy S and McCullough AJ; Practice Guideline Committee of the American Association for the Study of Liver Diseases; Practice Parameters Committee of the American College of Gastroenterology: Alcoholic liver disease. Hepatology 51: 307-328, 2010.

107. Wang M, Sun J, Jiang Z, Xie W and Zhang X: Hepatoprotective effect of kaempferol against alcoholic liver injury in mice. Am J Chin Med 43: 241-254, 2015.

108. French SW: The importance of CYP2E1 in the pathogenesis of alcoholic liver disease and drug toxicity and the role of the proteasome. Subcell Biochem 67: 145-164, 2013. 
109. Zhou B, Jiang Z, Li X and Zhang X: Kaempferol's protective effect on ethanol-induced mouse primary hepatocytes injury involved in the synchronous inhibition of SP1, Hsp70 and CYP2E1. Am J Chin Med 46: 1093-1110, 2018.

110. McCarthy MI: Genomics, type 2 diabetes, and obesity. N Engl J Med 363: 2339-2350, 2010.

111. Tilg $\mathrm{H}$ and Moschen AR: Adipocytokines: Mediators linking adipose tissue, inflammation and immunity. Nat Rev Immunol 6: 772-873, 2006.

112. Lee B, Kwon M, Choi JS, Jeong HO, Chung HY and Kim HR: Kaempferol isolated from nelumbo nucifera inhibits lipid accumulation and increases fatty acid oxidation signaling in adipocytes. J Med Food 18: 1363-1370, 2015.

113. Chang CJ, Tzeng TF, Liou SS, Chang YS and Liu IM: Kaempferol regulates the lipid-profile in high-fat diet-fed rats through an increase in hepatic PPAR $\alpha$ levels. Planta Med 77: 1876-1882, 2011.

114. Luo C, Yang H, Tang C, Yao G, Kong L, He H and Zhou Y: Kaempferol alleviates insulin resistance via hepatic IKK/NF- $\kappa \mathrm{B}$ signal in type 2 diabetic rats. Int Immunopharmacol 28: 744-750, 2015.

115. Chen X, Qian J, Wang L, Li J, Zhao Y, Han J, Khan Z, Chen X, Wang $J$ and Liang G: Kaempferol attenuates hyperglycemia-induced cardiac injuries by inhibiting inflammatory responses and oxidative stress. Endocrine 60: 83-94, 2018.

116. Zhang Y and Liu D: Flavonol kaempferol improves chronic hyperglycemia-impaired pancreatic beta-cell viability and insulin secretory function. Eur J Pharmacol 670: 325-332, 2011.

117. Kass DA: Getting better without AGE: New insights into the diabetic heart. Circ Res 92: 704-706, 2003.

118. Suchal K, Malik S, Khan SI, Malhotra RK, Goyal SN, Bhatia J, Ojha S and Arya DS: Molecular pathways involved in the amelioration of myocardial injury in diabetic rats by kaempferol. Int J Mol Sci 18: pii: E1001, 2017.

119. Alkhalidy H, Moore W, Wang A, Luo J, McMillan RP, Wang Y, Zhen W, Hulver MW and Liu D: Kaempferol ameliorates hyperglycemia through suppressing hepatic gluconeogenesis and enhancing hepatic insulin sensitivity in diet-induced obese mice. J Nutr Biochem 58: 90-101, 2018.

120. Kishore L, Kaur N and Singh R: Effect of Kaempferol isolated from seeds of Eruca sativa on changes of pain sensitivity in Streptozotocin-induced diabetic neuropathy. Inflammopharmacology 26: 993-1003, 2018.

121. Chawla A, Repa JJ, Evans RM and Mangelsdorf DJ: Nuclear receptors and lipid physiology: Opening the X-files. Science 294: 1866-1870, 2001

122. Hoang MH, Jia Y, Mok B, Jun HJ, Hwang KY and Lee SJ: Kaempferol ameliorates symptoms of metabolic syndrome by regulating activities of liver $X$ receptor- $\beta$. J Nutr Biochem 26: 868-875, 2015.

123. Fisher M: Injuries to the vascular endothelium: Vascular wall and endothelial dysfunction. Rev Neurol Dis 5 (Suppl 1): S4-S11, 2008.

124. Kim TH, Ku SK and Bae JS: Inhibitory effects of kaempferol-3-O-sophoroside on HMGB1-mediated proinflammatory responses. Food Chem Toxicol 50: 1118-1123, 2012.

125. ten Dijke P and Arthur HM: Extracellular control of TGFbeta signalling in vascular development and disease. Nat Rev Mol Cell Biol 8: 857-869, 2007

126. Chan MC, Hilyard AC, Wu C, Davis BN, Hill NS, Lal A, Lieberman J,Lagna $\mathrm{G}$ and Hata A: Molecular basis for antagonism between PDGF and the TGFbeta family of signalling pathways by control of miR-24 expression. EMBO J 29: 559-573, 2010.

127. Kim K, Kim S, Moh SH and Kang H: Kaempferol inhibits vascular smooth muscle cell migration by modulating BMP-mediated miR-21 expression. Mol Cell Biochem 407: 143-149, 2015

128. Ochiai A, Miyata S, Iwase M, Shimizu M, Inoue J and Sato R: Kaempferol stimulates gene expression of low-density lipoprotein receptor through activation of $\mathrm{Sp} 1$ in cultured hepatocytes. Sci Rep 6: 24940, 2016.

129. Tabas I, García-Cardeña G and Owens GK: Recent insights into the cellular biology of atherosclerosis. J Cell Biol 209: 13-22, 2015 .

130. Singh M, Ananthula S, Milhorn DM, Krishnaswamy G and Singh K: Osteopontin: A novel inflammatory mediator of cardiovascular disease. Front Biosci 12: 214-221, 2007.

131. Xiao HB, Lu XY, Sun ZL and Zhang HB: Kaempferol regulates OPN-CD44 pathway to inhibit the atherogenesis of apolipoprotein E deficient mice. Toxicol Appl Pharmacol 257: 405-411, 2011.
132. Keys A, Taylor HL, Blackburn H, Brozek J, Anderson JT and Simonson E: Mortality and coronary heart disease among men studied for 23 years. Arch Intern Med 128: 201-214, 1971.

133. Che J, Liang B, Zhang Y, Wang Y, Tang J and Shi G: Kaempferol alleviates ox-LDL-induced apoptosis by up-regulation of autophagy via inhibiting PI3K/Akt/mTOR pathway in human endothelial cells. Cardiovasc Pathol 31: 57-62, 2017.

134. Weisel JW, Stauffacher CV, Bullitt E and Cohen C: A model for fibrinogen: Domains and sequence. Science 230: 1388-1391, 1985.

135. Choi JH, Park SE, Kim SJ and Kim S: Kaempferol inhibits thrombosis and platelet activation. Biochimie 115: 177-186, 2015.

136. Mackman N: Triggers, targets and treatments for thrombosis. Nature 451: 914-918, 2008.

137. Begonja AJ, Gambaryan S, Geiger J, Aktas B, Pozgajova M, Nieswandt B and Walter U: Platelet NAD $(\mathrm{P}) \mathrm{H}$-oxidase-generated ROS production regulates alphaIIbbeta3-integrin activation independent of the NO/cGMP pathway. Blood 106: 2757-2760, 2005.

138. Wang SB, Jang JY, Chae YH, Min JH, Baek JY, Kim M, Park Y, Hwang GS, Ryu JS and Chang TS: Kaempferol suppresses collagen-induced platelet activation by inhibiting NADPH oxidase and protecting SHP-2 from oxidative inactivation. Free Radic Biol Med 83: 41-53, 2015.

139. Hampton BM, Schwartz SG, Brantley MA Jr and Flynn HW Jr: Update on genetics and diabetic retinopathy. Clin Ophthalmol 9: 2175-2193, 2015.

140. Behl T and Kotwani A: Exploring the various aspects of the pathological role of vascular endothelial growth factor (VEGF) in diabetic retinopathy. Pharmacol Res 99: 137-148, 2015.

141. Jenkins AJ, Joglekar MV, Hardikar AA, Keech AC, O'Neal DN and Januszewski AS: Biomarkers in diabetic retinopathy. Rev Diabet Stud 12: 159-195, 2015.

142. Li JK, Wei F, Jin XH, Dai YM, Cui HS and Li YM: Changes in vitreous VEGF, bFGF and fibrosis in proliferative diabetic retinopathy after intravitreal bevacizumab. Int J Ophthalmol 8: 1202-1206, 2015.

143. Sorenson CM, Wang S, Gendron R, Paradis H and Sheibani N: Thrombospondin-1 deficiency exacerbates the pathogenesis of diabetic retinopathy. J Diabetes Metab: (Suppl 12), 2013 doi: 10.4172/2155-6156.S12-005.

144. Wu Y, Zhang Q and Zhang R: Kaempferol targets estrogen-related receptor a and suppresses the angiogenesis of human retinal endothelial cells under high glucose conditions. Exp Ther Med 14: 5576-5582, 2017.

145. Xu XH, Zhao C, Peng Q, Xie P and Liu QH: Kaempferol inhibited VEGF and PGF expression and in vitro angiogenesis of HRECs under diabetic-like environment. Braz J Med Biol Res 50: e5396, 2017.

146. Chin HK, Horng CT, Liu YS, Lu CC, Su CY, Chen PS, Chiu HY, Tsai FJ, Shieh PC and Yang JS: Kaempferol inhibits angiogenic ability by targeting VEGF receptor- 2 and downregulating the PI3K/AKT, MEK and ERK pathways in VEGF-stimulated human umbilical vein endothelial cells. Oncol Rep 39: 2351-2357, 2018

147. Zhang YW, Shi J, Li YJ and Wei L: Cardiomyocyte death in doxorubicin-induced cardiotoxicity. Arch Immunol Ther Exp (Warsz) 57: 435-445, 2009

148. Kawamura T, Hasegawa K, Morimoto T, Iwai-Kanai E, Miyamoto S, Kawase Y, Ono K, Wada H, Akao M and Kita T: Expression of p300 protects cardiac myocytes from apoptosis in vivo. Biochem Biophys Res Commun 315: 733-738, 2004.

149. Xiao J, Sun GB, Sun B, Wu Y, He L, Wang X, Chen RC, Cao L, Ren XY and Sun XB: Kaempferol protects against doxorubicin-induced cardiotoxicity in vivo and in vitro. Toxicology 292: 53-62, 2012.

150. Liu J, Xin L, Benson VL, Allen DG and Ju YK: Store-operated calcium entry and the localization of STIM1 and Orail proteins in isolated mouse sinoatrial node cells. Front Physiol 6: 69, 2015.

151. Swulius MT and Waxham MN: Ca(2+)/calmodulin-dependent protein kinases. Cell Mol Life Sci 65: 2637-2657, 2008.

152. Wang Y, Cui H, Wang W, Zhao B and Lai J: The region-specific activation of $\mathrm{Ca} 2+/$ calmodulin dependent protein kinase II and extracellular signal-regulated kinases in hippocampus following chronic alcohol exposure. Brain Res Bull 89: 191-196, 2012.

153. Swaminathan PD, Purohit A, Soni S, Voigt N, Singh MV, Glukhov AV, Gao Z, He BJ, Luczak ED, Joiner ML, et al: Oxidized CaMKII causes cardiac sinus node dysfunction in mice. J Clin Invest 121: 3277-3288, 2011. 
154. Schiattarella GG and Hill JA: Inhibition of hypertrophy is a good therapeutic strategy in ventricular pressure overload. Circulation 131: 1435-1447, 2015.

155. Rose BA, Force T and Wang Y: Mitogen-activated protein kinase signaling in the heart: Angels versus demons in a heart-breaking tale. Physiol Rev 90: 1507-1546, 2010.

156. Feng H, Cao J, Zhang G and Wang Y: Kaempferol attenuates cardiac hypertrophy via regulation of ASK1/MAPK signaling pathway and oxidative stress. Planta Med 83: 837-845, 2017.

157. Weng X, Yu L, Liang P, Chen D, Cheng X, Yang Y, Li L, Zhang T, Zhou B, Wu X, et al: Endothelial MRTF-A mediates angiotensin II induced cardiac hypertrophy. J Mol Cell Cardiol 80: 23-33, 2015.

158.Zeisberg EM, Tarnavski O, Zeisberg M, Dorfman AL, McMullen JR, Gustafsson E, Chandraker A, Yuan X, Pu WT, Roberts AB, et al: Endothelial-to-mesenchymal transition contributes to cardiac fibrosis. Nat Med 13: 952-961, 2007.

159. Liu Y, Gao L, Guo S, Liu Y, Zhao X, Li R, Yan X, Li Y, Wang S, Niu X, et al: Kaempferol alleviates angiotensin II-induced cardiac dysfunction and interstitial fibrosis in mice. Cell Physiol Biochem 43: 2253-2263, 2017.

160. Fan Q, Chen L, Cheng S, Li F, Lau WB, Wang le F and Liu JH: Aging aggravates nitrate-mediated ROS/RNS changes. Oxid Med Cell Longev 2014: 376515, 2014

161. Juhaszova M, Zorov DB, Yaniv Y, Nuss HB, Wang S and Sollott SJ: Role of glycogen synthase kinase-3beta in cardioprotection. Circ. Res 104: 1240-1252, 2009.

162. Suchal K, Malik S, Gamad N, Malhotra RK, Goyal SN, Chaudhary U, Bhatia J, Ojha S and Arya DS: Kaempferol attenuates myocardial ischemic injury via inhibition of MAPK signaling pathway in experimental model of myocardial ischemia-reperfusion injury. Oxid Med Cell Longev 2016: 7580731, 2016.

163. Shen AC and Jennings RB: Kinetics of calcium accumulation in acute myocardial ischemic injury. Am J Pathol 67: 441-452, 1972.

164. Guo Z, Liao Z, Huang L, Liu D, Yin D and He M: Kaempferol protects cardiomyocytes against anoxia/reoxygenation injury via mitochondrial pathway mediated by SIRT1. Eur J Pharmacol 761: 245-253, 2015.

165. Khader A, Yang WL, Kuncewitch M, Jacob A, Prince JM, Asirvatham JR, Nicastro J, Coppa GF and Wang P: Sirtuin 1 activation stimulates mitochondrial biogenesis and attenuates renal injury after ischemia-reperfusion. Transplantation 98: $148-156,2014$

166. Zhou M, Ren H, Han J, Wang W, Zheng Q and Wang D: Protective effects of kaempferol against myocardial Ischemia/Reperfusion injury in isolated rat heart via antioxidant activity and inhibition of glycogen synthase kinase-3 $\beta$. Oxid Med Cell Longev 2015 481405,2015

167. Lei Y, Chen J, Zhang W, Fu W, Wu G, Wei H, Wang Q and Ruan J: In vivo investigation on the potential of galangin, kaempferol and myricetin for protection of D-galactose-induced cognitive impairment. Food Chem 135: 2702-2707, 2012.

168. Zhong SZ, Ge QH, Qu R, Li Q and Ma SP: Paeonol attenuates neurotoxicity and ameliorates cognitive impairment induced by d-galactose in ICR mice. J Neurol Sci 277: 58-64, 2009.

169. Palsamy P, Sivakumar S and Subramanian S: Resveratrol attenuates hyperglycemia-mediated oxidative stress, proinflammatory cytokines and protects hepatocytes ultrastructure in streptozotocin-nicotinamide-induced experimental diabetic rats. Chem Biol Interact 186: 200-210, 2010

170. McEwen BS and Stellar E: Stress and the individual. Mechanisms leading to disease. Arch Intern Med 153: 2093-2101, 1993.

171. Whooley MA and Simon GE: Managing depression in medical outpatients. N Engl J Med 343: 1942-1950, 2000.

172. Park SH, Sim YB, Han PL, Lee JK and Suh HW: Antidepressantlike effect of kaempferol and quercitirin, isolated from opuntia ficus-indica var. saboten. Exp Neurobiol 19: 30-38, 2010.

173. Reeve A, Simcox E and Turnbull D: Ageing and Parkinson's disease: Why is advancing age the biggest risk factor? Ageing Res Rev 14: 19-30, 2014

174. Tian L, Karimi M, Loftin SK, Brown CA, Xia H, Xu J, Mach RH and Perlmutter JS: No differential regulation of dopamine transporter (DAT) and vesicular monoamine transporter 2 (VMAT2) binding in a primate model of Parkinson disease. PLoS One 7 e31439, 2012.

175. Han X, Sun S, Sun Y, Song Q, Zhu J, Song N, Chen M, Sun T, Xia M, Ding J, et al: Small molecule-driven NLRP3 inflammation inhibition via interplay between ubiquitination and autophagy: Implications for Parkinson disease. Autophagy: 1-22, 2019 10.1080/15548627.2019.1596481 (Epub ahead of print).
176. Li S and Pu XP: Neuroprotective effect of kaempferol against a 1-methyl-4-phenyl-1,2,3,6-tetrahydropyridine-induced mouse model of Parkinson's disease. Biol Pharm Bull 34: 1291-1296, 2011.

177. Ma Z, Li C, Qiao Y, Lu C, Li J, Song W, Sun J, Zhai X, Niu J, Ren Q and Wen A: Safflower yellow B suppresses HepG2 cell injury induced by oxidative stress through the AKT/Nrf2 pathway. Int J Mol Med 37: 603-612, 2016.

178. Ren R, Shi C, Cao J, Sun Y, Zhao X, Guo Y, Wang C, Lei H, Jiang H, Ablat N, et al: Neuroprotective effects of A standardized flavonoid extract of safflower against neurotoxin-induced cellular and animal models of Parkinson's disease. Sci Rep 6: 22135, 2016.

179. Jang JY, Kim HN, Kim YR, Choi YW, Choi YH, Lee JH, Shin HK and Choi BT: Hexane extract from Polygonum multiflorum attenuates glutamate-induced apoptosis in primary cultured cortical neurons. J Ethnopharmacol 145: 261-268, 2013.

180. Yang EJ, Kim GS, Jun M and Song KS: Kaempferol attenuates the glutamate-induced oxidative stress in mouse-derived hippocampal neuronal HT22 cells. Food Funct 5: 1395-1402, 2014.

181. Lai TW, Zhang S and Wang YT: Excitotoxicity and stroke: Identifying novel targets for neuroprotection. Prog Neurobiol 115: 157-188, 2014.

182. Zhou X, Sun X, Gong X, Yang Y, Chen C, Shan G and Yao Q: Astragaloside IV from Astragalus membranaceus ameliorates renal interstitial fibrosis by inhibiting inflammation via TLR4/NF-KB in vivo and in vitro. Int Immunopharmacol 42: 18-24, 2017.

183. Zhang H, Park JH, Maharjan S, Park JA, Choi KS, Park H, Jeong Y, Ahn JH, Kim IH, Lee JC, et al: Sac-1004, a vascular leakage blocker, reduces cerebral ischemia-reperfusion injury by suppressing blood-brain barrier disruption and inflammation. J Neuroinflammation 14: 122, 2017.

184. Cheng X, Yang YL, Yang H, Wang YH and Du GH: Kaempferol alleviates LPS-induced neuroinflammation and BBB dysfunction in mice via inhibiting HMGB1 release and down-regulating TLR4/MyD88 pathway. Int Immunopharmacol 56: 29-35, 2018.

185. Wu B, Luo H, Zhou X, Cheng CY, Lin L, Liu BL, Liu K, Li P and Yang H: Succinate-induced neuronal mitochondrial fission and hexokinase II malfunction in ischemic stroke: Therapeutical effects of kaempferol. Biochim Biophys Acta 1863: 2307-2318, 2017.

186. Zhao J, Shu B, Chen L, Tang J, Zhang L, Xie J, Liu X, Xu Y and Qi S: Prostaglandin E2 inhibits collagen synthesis in dermal fibroblasts and prevents hypertrophic scar formation in vivo. Exp Dermatol 25: 604-610, 2016.

187. Ledon JA, Savas J, Franca K, Chacon A and Nouri K: Intralesional treatment for keloids and hypertrophic scars: A review. Dermatol Surg 39: 1745-1757, 2013

188. Sarrazy V, Billet F, Micallef L, Coulomb B and Desmoulière A: Mechanisms of pathological scarring: Role of myofibroblasts and current developments. Wound Repair Regen 19 (Suppl 1): S10-S15, 2011

189. Li H, Yang L, Zhang Y and Gao Z: Kaempferol inhibits fibroblast collagen synthesis, proliferation and activation in hypertrophic scar via targeting TGF- $\beta$ receptor type I. Biomed Pharmacother 83: 967-974, 2016.

190. Rietjens IM, Boersma MG, van der Woude H, Jeurissen SM, Schutte ME and Alink GM: Flavonoids and alkenylbenzenes: Mechanisms of mutagenic action and carcinogenic risk. Mutat Res 574: 124-138, 2005.

191. Sheng WY, Chen YR and Wang TC: A major role of PKC theta and NFkappaB in the regulation of hTERT in human T lymphocytes. FEBS Lett 580: 6819-6824, 2006.

192. Park SE, Sapkota K, Kim S, Kim H and Kim SJ: Kaempferol acts through mitogen-activated protein kinases and protein kinase $\mathrm{B} / \mathrm{AKT}$ to elicit protection in a model of neuroinflammation in BV2 microglial cells. Br J Pharmacol 164: 1008-1025, 2011.

193. Wang J, Fang X, Ge L, Cao F, Zhao L, Wang Z and Xiao W: Antitumor, antioxidant and anti-inflammatory activities of kaempferol and its corresponding glycosides and the enzymatic preparation of kaempferol. PLoS One 13: e0197563, 2018.

194. Noroozi M, Angerson WJ and Lean ME: Effects of flavonoids and vitamin $\mathrm{C}$ on oxidative DNA damage to human lymphocytes. Am J Clin Nutr 67: 1210-1218, 1998

195. Bestwick CS, Milne L, Pirie L and Duthie SJ: The effect of short-term kaempferol exposure on reactive oxygen levels and integrity of human (HL-60) leukaemic cells. Biochim Biophys Acta 1740: 340-349, 2005.

196. Sahu SC and Gray GC: Kaempferol-induced nuclear DNA damage and lipid peroxidation. Cancer Lett 85: 159-164, 1994. 
197. Liesveld JL, Abboud CN, Lu C, McNair C, Menon A, Smith A Rosell K and Rapoport AP: Flavonoid effects on normal and leukemic cells. Leuk Res 27: 517-527, 2003.

198. Das A, Majumder D and Saha C: Correlation of binding efficacies of DNA to flavonoids and their induced cellular damage. J Photochem Photobiol B 170: 256-262, 2017.

199. Cos P, Calomme M, Sindambiwe JB, De Bruyne T, Cimanga K, Pieters L, Vlietinck AJ and Vanden Berghe D: Cytotoxicity and lipid peroxidation-inhibiting activity of flavonoids. Planta Med 67: 515-519, 2001.

200. Gupta A, Kaur CD, Saraf S and Saraf S: Formulation, characterization, and evaluation of ligand-conjugated biodegradable quercetin nanoparticles for active targeting. Artif Cells Nanomed Biotechnol 44: 960-970, 2016.

201. Qian YS, Ramamurthy S, Candasamy M, Shadab M, Kumar RH and Meka VS: Production, characterization and evaluation of kaempferol nanosuspension for improving oral bioavailability. Curr Pharm Biotechnol 17: 549-555, 2016.

202. Resende FA, Vilegas W, Dos Santos LC and Varanda EA: Mutagenicity of flavonoids assayed by bacterial reverse mutation (Ames) test. Molecules 17: 5255-5268, 2012.
203. Polyakov NE and Kispert LD: Water soluble biocompatible vesicles based on polysaccharides and oligosaccharides inclusion complexes for carotenoid delivery. Carbohydr Polym 128: 207-219, 2015

204.Xu W, Wen M, Yu J, Zhang Q, Polyakov NE, Dushkin AV and $\mathrm{Su} \mathrm{W}$ : Mechanochemical preparation of kaempferol intermolecular complexes for enhancing the solubility and bioavailability. Drug Dev Ind Pharm 44: 1924-1932, 2018.

205. Lemos C, Peters GJ, Jansen G, Martel F and Calhau C: Modulation of folate uptake in cultured human colon adenocarcinoma Caco-2 cells by dietary compounds. Eur J Nutr 46: 329-336, 2007.

206. Sunoqrot S, Bae JW, Pearson RM, Shyu K, Liu Y, Kim DH and Hong S: Temporal control over cellular targeting through hybridization of folate-targeted dendrimers and PEG-PLA nanoparticles. Biomacromolecules 13: 1223-1230, 2012.

(c) (i) $\Theta$ This work is licensed under a Creative Commons Attribution-NonCommercial-NoDerivatives 4.0 International (CC BY-NC-ND 4.0) License. 